\section{Pacific Northwest}

National Laboratory

Operated by Battelle for the

U.S. Department of Energy

\title{
Advanced CHP Control Algorithms: Scope Specification
}

S Katipamula

MR Brambley

April 2006

Prepared for the U.S. Department of Energy

under Contract DE-AC05-76RL01830

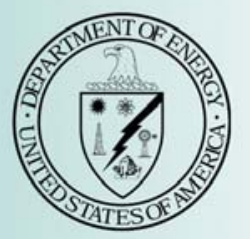




\section{LIMITED DISTRIBUTION NOTICE}

This document copy, since it is transmitted in advance of patent clearance, is made available in confidence solely for use in performance of work under contracts with the U.S. Department of Energy. This document is not to be published nor its contents otherwise disseminated or used for purposes other than specified above before patent approval for such release or use has been secured, upon request, from Intellectual Property Services, Pacific Northwest National Laboratory, Richland, Washington 99352.

(A) This document was printed on recycled paper.

9/2003 


\section{Advanced CHP Control Algorithms: Scope Specification}

S Katipamula

MR Brambley

April 2006

Prepared for

the U.S. Department of Energy

under Contract DE-AC05-76RL01830

Pacific Northwest National Laboratory

Richland, Washington 99352 


\section{Acknowledgements}

This work was supported the Distributed Generation Program of the Office of Electricity Delivery and Electric Reliability of the U.S. Department of Energy. The authors wish to thank Debbie Haught, the DOE Program Manager, and Mario Sciulli, Program Manager at the National Energy Technology Laboratory, for their support and guidance in the performance of this work. Members of the project advisory panel also provided valuable input through their review of project plans and reports. Their guidance is critical to the successful performance of this project. The authors would also like to thank the following people and organizations who kindly participated in surveys, meetings, and telephone discussions, provided tours of their facilities, and shared their knowledge and experiences on the commissioning and operation of distributed generation and combined cooling, heating and power facilities. Their input is crucial to guiding the project to delivery products that address practical issues experienced in the field.

Kevin Best - RealEnergy

Craig Erickson - Equity Office Properties Trust

Joe Frankini - Equity Office Properties Trust

Steve Gable - Honeywell

Cons Gattuso - Equity Office Properties Trust

Reinhard Rademacher - University of Maryland

Sumit Ray - Trammel Crow

Bill Rogers - Beaufort Marine Corp Air Station

Duane Sanger - Portland Sewer Treatment Plant

Neil Tisdale - Beaufort Marine Corp Air Station

\section{Project Advisory Panel}

Todd Amundson, Bonneville Power Administration

Gordon Bloomquist, Washington State University Extension Program and Northwest CHP

Application Center

Michael O'Callaghan, United Technologies Research Center

Steve Gable, Honeywell

Patti Garland, Oak Ridge National Laboratory

Carlos Haiad, Southern California Edison

Chris Marnay, Lawrence Berkeley National Laboratory

Abdi Zaltash, Oak Ridge National Laboratory 


\section{Table of Contents}

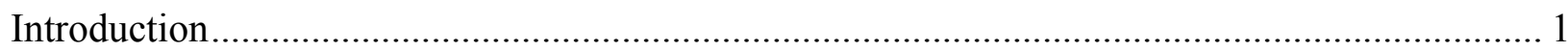

Background and Definitions ............................................................................................ 2

Combined Cooling, Heating and Power (CHP) Systems ................................................ 2

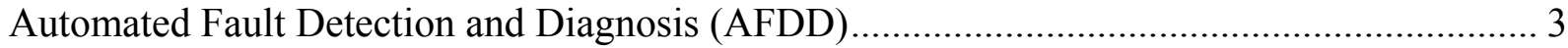

Conditioned Based Maintenance (CBM) .................................................................... 3

Automated Reconfiguration and Correction .................................................................. 4

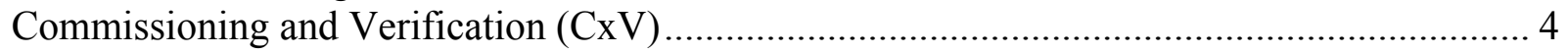

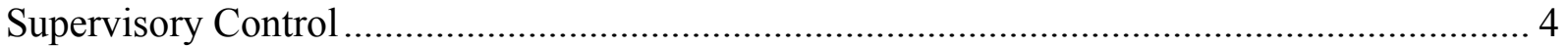

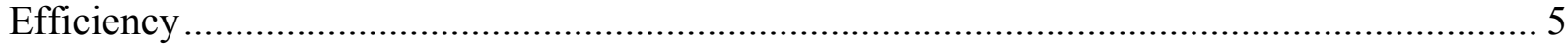

CHP System Efficiency - CHP Fuel Utilization Efficiency ........................................ 5

Subsystem and Component Efficiencies.................................................................... 8

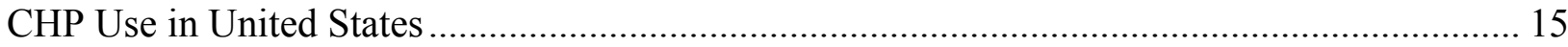

Distributed Energy and Combined Cooling, Heating and Power Technologies ........................ 19

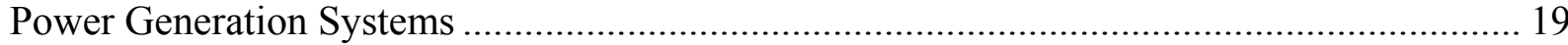

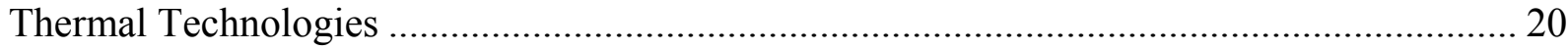

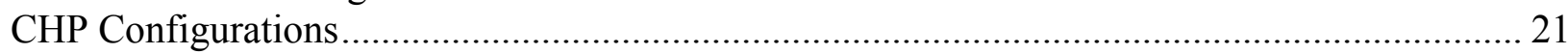

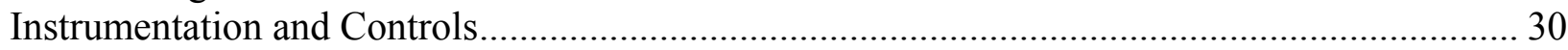

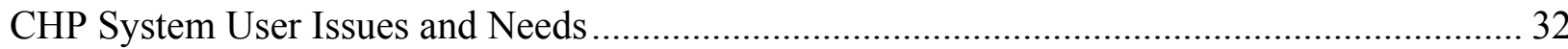

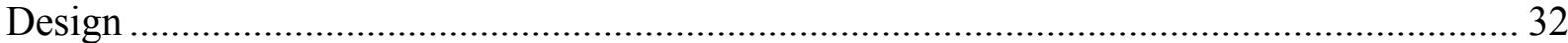

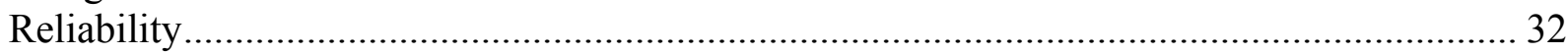

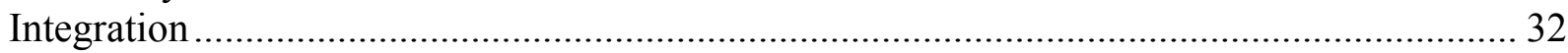

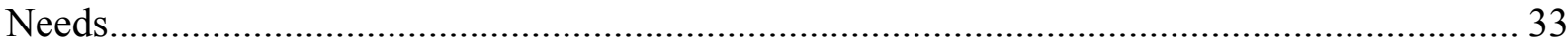

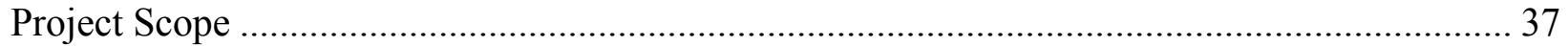




\section{Introduction}

Pacific Northwest National Laboratory (PNNL) is assisting the U.S. Department of Energy (DOE) Distributed Energy (DE) Program by developing advanced control algorithms that would lead to development of tools to enhance performance and reliability, and reduce emissions of distributed energy technologies, including combined cooling, heating and power (CHP) technologies ${ }^{1}$.

The primary objective of this multiyear project is to develop algorithms for combined cooling, heating and power systems. These algorithms will ensure optimal performance, increase reliability, and lead to the goal of clean, efficient, reliable and affordable next generation integrated energy systems.

As part of the project, in FY05, an expert project advisory panel (PAP) was formed to help guide and review progress of the proposed multiyear research effort. The advisory panel included representatives from: 1) Honeywell Labs, 2) United Technologies Research Center (UTRC), 3) Northwest CHP Application Center, 4) Bonneville Power Administration (BPA) and 5) Southern California Edison (SCE).

This report provides background information and a list of algorithms that will be developed, the relationships among them, and the operations and maintenance (O\&M) capabilities they will enable.

Detailed system level functionality and structure, detailed specification of the algorithms, and associating the algorithms with specific capabilities and tools that they will enable will be developed as part of the next task and are not covered in this report.

In the next section we provide background information and define various terms that are used throughout the report. This section is followed by a summary of the current market for CHP systems. We then introduce various CHP technologies, followed by a summary of interviews conducted with CHP owners and users on their needs and issues with CHP systems. This is followed by a section on potential CHP configurations, and instrumentation and controls requirements. The last section describes the scope of the activities that PNNL will undertake.

\footnotetext{
${ }^{1}$ In the open literature, several different names are used for combined cooling, heating and power systems, although they use the same technologies. In the next section, we provide the actual definition for combined cooling, heating and power and list other names associated with it.
} 


\section{Background and Definitions}

In this section, we provide background information and definitions of some of the terms that are used in the document.

\section{Combined Cooling, Heating and Power (CHP) Systems}

The Energy Information Administration (EIA) defines a system designed to produce both heat (used for both heating as well as cooling) and electricity from a single heat source ${ }^{2}$ as a combined heat and power ${ }^{3}$ (CHP) system. The terms "combined heat and power," "cooling, heating, and power" and CHP are used synonymously in the literature. All refer to a CHP system is an integrated system (Figure 1) "located at or near a building or facility, satisfying at least a portion of the facility's electrical demand, and utilizing the heat generated by the electric (or shaft) power generation equipment to provide heating, cooling, and/or dehumidification to a building and/or industrial processes."

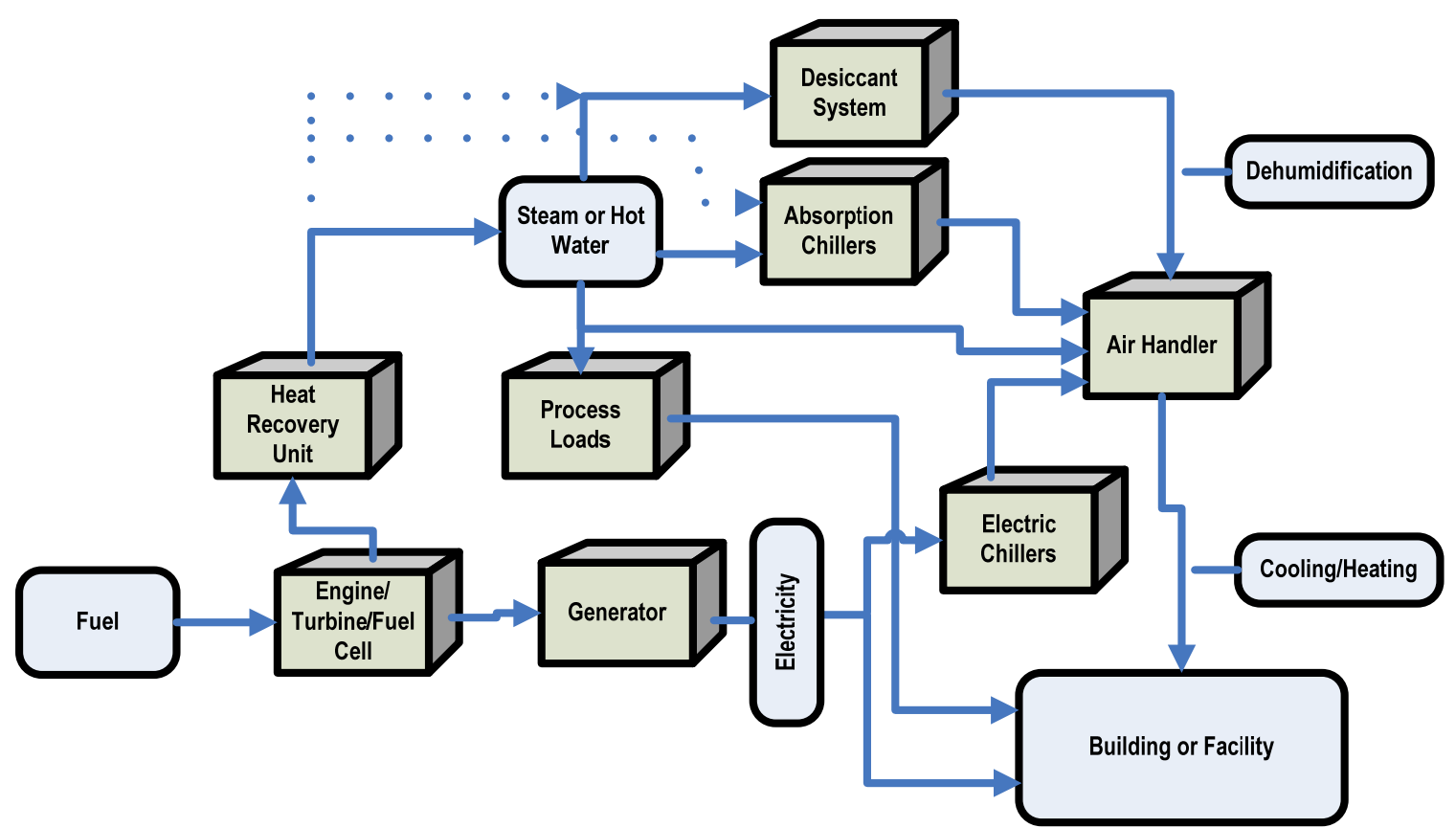

Figure 1 -Comprehensive Schematic Diagram of a CHP System (adopted from MAC $\left.2003^{4}\right)$.

\footnotetext{
${ }^{2}$ According to Energy Information Agency (EIA), the term CHP is being used in place of the term "cogenerator" that was used by EIA in the past. CHP better describes the facilities because some of the plants included do not produce heat and power in a sequential fashion and, as a result, do not meet the legal definition of cogeneration specified in the Public Utility Regulatory Policies Act (PURPA).

${ }^{3}$ Other terms in the literature for CHP systems include building combined heat and power (BCHP), combined cooling, heating and power (CCHP), combined heat and power for buildings, and integrated energy systems.

${ }^{4}$ Midwest CHP Application Center (MAC). 2003. Combined Heat \& Power (CHP) Resource Guide, University of Illinois at Chicago, and Avalon Consulting, Inc., Chicago, IL.

http://www.chpcentermw.org/pdfs/chp_resource_guide_2003sep.pdf
} 


\section{Automated Fault Detection and Diagnosis (AFDD)}

Automated fault detection and diagnosis (AFDD) is an automatic process by which faulty (improper) operation, degraded performance, or broken components in a physical system are detected and diagnosed.

AFDD consists of two primary processes: fault detection and fault diagnosis (Figure 2). The first, fault detection, is the process of determining that some fault has occurred in the system. The second, fault diagnosis, consists of two sub-processes, fault isolation and fault identification. Fault isolation involves isolating the specific fault that occurred including determining the kind of fault, the location of the fault, the time of detection, and the cause of the fault. Fault identification, includes determining the size and time-variant behavior of a fault.

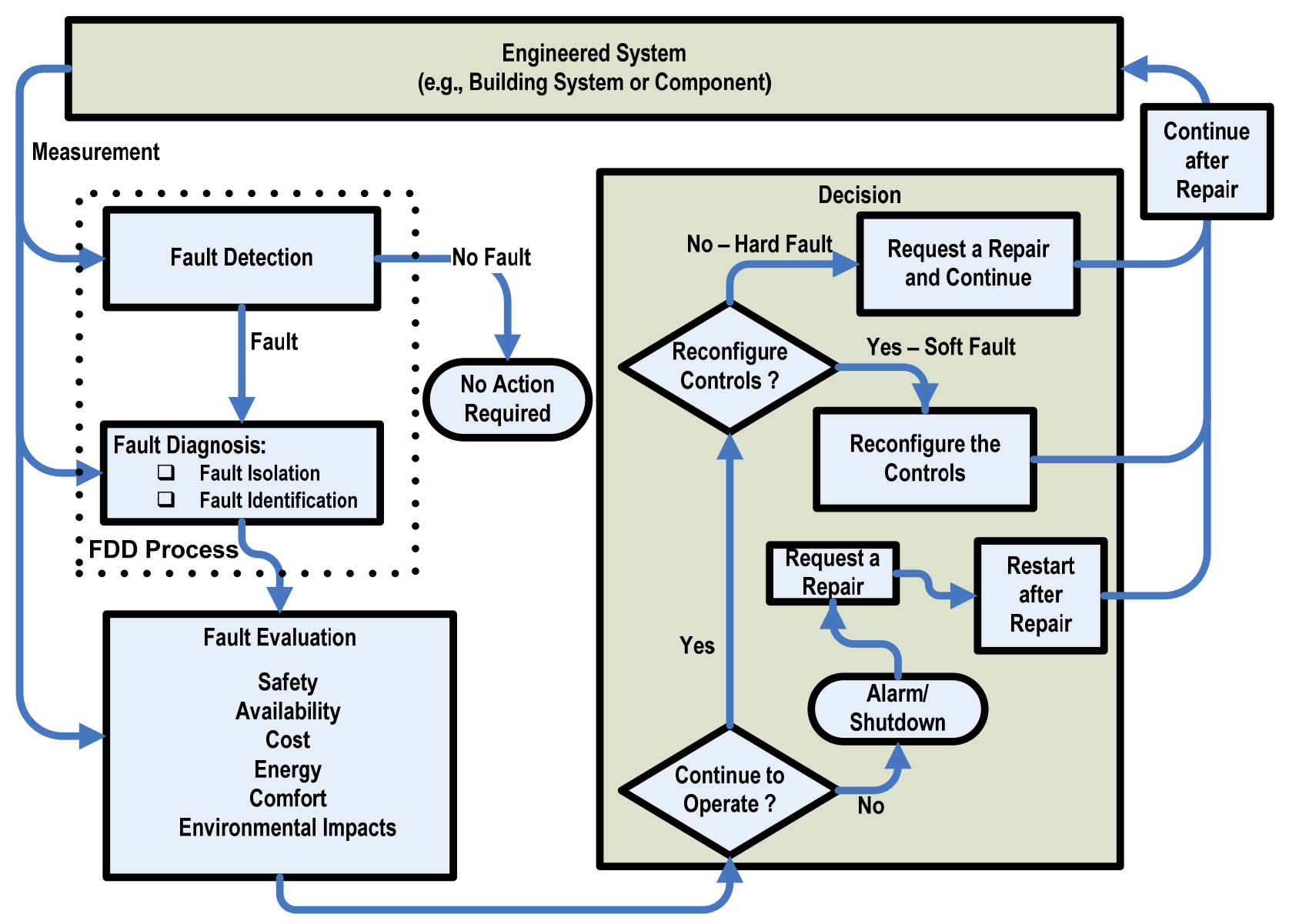

Figure 2 - Generic Application of Fault Detection and Diagnostics to Operation and Maintenance of Engineered Systems

\section{Conditioned Based Maintenance (CBM)}

Conditioned based maintenance $(\mathrm{CBM})$ is a process by which operation and maintenance of engineered systems and equipment are based on their current states, including any faults that are 
present and the severity of the fault conditions. Predictive maintenance takes this one step further planning and managing maintenance by using projected severity of performance degradation, existing fault conditions, severity of faults, and projections of when equipment will fail or reach unacceptable performance levels beyond which operation should not continue.

A generic conditioned-based operation and maintenance process can be viewed as having four distinct functional processes, as shown in Figure 2. The first two steps are generally referred to as the AFDD process. In the first step the physical system or device is monitored and any abnormal conditions (problems) are detected. This step is generally referred to as fault detection. When an abnormal condition is detected, then fault diagnosis is used to isolate and identify the fault and determine its causes.

Following diagnosis, fault evaluation assesses the size and significance of the impact on system performance (in terms of energy use, cost, availability, or effects on other performance indicators). Based on the fault evaluation, a decision is then made on how to respond to the fault (e.g., by taking a corrective action or possibly even no action). Together these four steps enable condition-based maintenance.

\section{Automated Reconfiguration and Correction}

If a fault is detected, diagnosed (isolated), and evaluated but found to not present sufficient risk to shut down operation immediately, the next issue to address is whether the fault can be corrected simply by changing the control software code or values of parameters such as set points or operating parameters. These faults are sometimes called "soft" faults because they do not require physical repair of the system or cause the system to stop operating. Because they are amenable to correction by software changes or changes in the values of parameters, these faults can be automatically corrected. When corrected automatically, the system continues to operate properly without interruption. Controls with this type of reconfiguration capability are also referred to as fault tolerant controls.

\section{Commissioning and Verification (CxV)}

CHP system commissioning should involve active testing of components and sub-systems as one of its core activities, including a systematic series of activities, starting in the planning phase, aimed at ensuring correct operation of the CHP system. Commissioning verification $(\mathrm{CxV})$ is a process by which the actual performance of the individual components in a CHP system and the performance of the CHP system as a whole are verified to comply with the designers' and manufacturers' recommended performance. A goal of this project is to automate parts of $\mathrm{CxV}$ for $\mathrm{CHP}$ systems. Although the $\mathrm{CxV}$ process can include active testing of components and subsystems, in this project the intent is just to verify the performance to ensure that the system has been adequately commissioned and to provide indicators of commissioning still needed when deficiencies are found.

\section{Supervisory Control}


Supervisory control is a process that provides plant-wide (CHP system-wide) management and coordination of multiple system components, and leads to improvement in plant efficiency and/or operating cost reductions. Some examples of supervisory controls as they relate to CHP system include scheduling, deciding how much electricity to generate or how much heat and/or cooling to produce at each time (e.g., follow the electric load or follow the thermal load), which components to run at any given time if there are any redundant components, like parallel pumps, which applications to run as a function of time and conditions, what fuel to use for fuel flexible components.

\section{Efficiency}

The efficiency of a CHP system can be defined in several different ways. In addition, each component of the CHP system (prime mover, heat recovery unit, or absorption chiller) has its own efficiency. Because it is difficult to find a single performance metric that would address all possible applications of CHP systems ${ }^{5}$ and each definition has its own advantage, it is appropriate to report application-specific efficiencies. Defining a meaningful system-level efficiency is somewhat problematic because of the different forms of energy and their differing qualities. Nevertheless a frequently-used measure of CHP-system efficiency is the fuel utilization efficiency.

\section{CHP System Efficiency - CHP Fuel Utilization Efficiency}

The most commonly used CHP system-level efficiency is the fuel utilization efficiency $\left(\eta_{F U F}\right)$, which is based on the first law of thermodynamics and is the ratio of the sum of all useful outputs (electrical and thermal) to the energy content of the fuel input:

$$
\eta_{F U F}=\frac{\left(W_{\text {Elec }}+\sum_{i} Q_{t h, i}\right)}{Q_{\text {Fuel }}},
$$

where $W_{\text {Elec }}$ is the net electrical power output, $Q_{\text {th,i }}$ represents the net rate of useful thermal energy output from thermal recovery process $i$ with the sum being over all thermal recovery processes in the system, and $Q_{\text {Fuel }}$ is the total rate of input of fuel energy to the CHP system. For systems with fuel used for supplemental heating (e.g., for a heat recovery unit, steam generator, or desiccant regenerator), $Q_{\text {Fuel }}$ is the sum over all fuel inputs to the system, i.e.,

$$
Q_{\text {Fuel }}=\sum_{j} Q_{\text {Fuel, },}
$$

where $Q_{f u e l, j}$ is the rate of fuel energy input at point $j$ in the system (e.g., to the prime mover or for supplemental heating of exhaust gases before entering the heat recovery unit) with the sum being over all fuel inputs to the CHP system. These fuel inputs may include the same fuel (e.g.,

\footnotetext{
${ }^{5}$ Sweetser, R. and H. Bruce. 2004. "Single Cooling, Heating, and Power (CHP) Performance Metric and Energy Savings Assessment." http://www.exergypartners.com/PDF/Metric\%20Project.pdf
} 
natural gas) introduced at several different points in the system or may be different fuels (e.g., diesel fuel for a reciprocating engine prime mover and natural gas for supplemental heat elsewhere in the system). The fuel energy may be based on the lower heating value (LHV) or higher heating value (HHV) of the fuel. By convention, the gas turbine industry uses the lower heating value to characterize energy use and calculate efficiencies, while the natural gas distribution and electric power generation industries use the HHV for sales and to characterize natural-gas energy use. ${ }^{6}$ Use of the LHV for determining energy use or the efficiency of microturbines and reciprocating engines in CHP systems seems reasonable because the products of combustion (exhaust) leave the turbine or engine at conditions at which the water is in vapor phase. For monitoring CHP system performance and detecting degradation over time, either the LHV or the HHV can be used as long as the use is consistent. For comparisons to benchmarks such as data from manufacturers, care must be taken to ensure that the LHV or HHV is used consistently in determination of the benchmark and in calculations of monitored performance.

Although $\eta_{F U F}$ is the most commonly used indicator of CHP system efficiency, it fails to account for the quality (exergy) of the different energy streams.

Different forms of energy (e.g., electricity and heat) have different qualities or values (exergies). Even heat at one temperature has greater quality than heat at a lower temperature. Because of these differences in the quality of the energy outputs of the CHP system and the cascading nature of the recovery processes, a second law efficiency may be more appropriate for measuring the efficiency of CHP systems. Second law efficiencies are not widely understood in practice and, therefore, may present practical problems for use in the field.

Some investigators have proposed additional efficiencies based on the first law of thermodynamics to complement the fuel utilization efficiency as defined above. For example, Horlock (1997) ${ }^{7}$ gives an equivalent electrical generation efficiency based on the first law of thermodynamics, which was later reintroduced by Sweetser and Hadman $(2004)^{5}$ as an electric generation effectiveness for CHP systems. In defining this metric, the primary purpose of the CHP system is considered to be providing thermal energy with electricity being a byproduct. Taking this perspective, Sweetser and Hadman provide the following definition for CHP electrical effectiveness:

\section{CHP electrical effectiveness is defined as the net electrical output divided by the incremental fuel consumption of the CHP system over and above the fuel that would have been required to produce the useful thermal output of the system by conventional means. ${ }^{5}$}

This metric measures the effectiveness of the CHP system in generating electric power, assuming that only the energy content of the fuel that would not be used to satisfy the thermal needs of the site is the input to the electric generation process. The CHP electrical effectiveness $\left(\eta_{\mathrm{EE}}\right)$ is then defined as:

\footnotetext{
${ }^{6}$ Energy Nexus Group. 2002. Technology Characterization: Microturbines. Prepared for the Environmental Protection Agency, Climate Protection Partnership Division. Access on May 24, 2006, on the world wide web at http://www.epa.gov/chp/pdf/microturbines.pdf.

${ }^{7}$ Horlock, J. H. 1997. Cogeneration - Combined Heat and Power (CHP). $2^{\text {nd }}$ edition. Krieger Publishing Company, Malabar, Florida.
} 


$$
\eta_{E E}=\frac{W_{E l e c}}{\left(Q_{\text {Fuel }}-\sum_{i} Q_{t h, i} / \alpha_{i}\right)},
$$

where $\alpha_{i}$ represents the efficiency of the $i$ th conventional technology that otherwise would be used to provide the useful thermal energy output of the system. This effectiveness together with $\eta_{F U F}$ can be used to measure and monitor the effectiveness of the CHP system.

Unfortunately, this formulation of the electrical effectiveness depends strongly on the assumption that thermal energy is the primary output of the system. In most cases though, electricity is the output of higher economic value of a CHP system and consequently the electrical load is followed and the thermal energy recovered is used to the extent to which on-site thermal loads require it. Furthermore, most CHP systems integrated with building applications (integrated energy systems) produce electricity first and then recover "waste" heat for thermal applications. This arrangement begs the question of whether it is reasonable for such configurations to consider thermal energy the primary intended output of the system.

A second law efficiency or exergy efficiency $(\psi)$ is a better measure of overall system efficiency for complex energy systems such as CHP. It is defined as the ratio of usable exergy output ( $\left.\mathrm{E}_{\text {out }}\right)$ to exergy input $\left(\mathrm{E}_{\text {in }}\right)$, i.e.,

$$
\Psi=\mathrm{E}_{\text {out }} / \mathrm{E}_{\text {in }} .
$$

This second law efficiency establishes how well the energy resource is utilized across the entire multi-process CHP system ${ }^{8}$ and accounts for the differences in quality of the various input and output streams.

Analysis by Erstevag and Nesheim (2005) ${ }^{9}$ shows that $\eta_{\mathrm{EE}}$ and other adjusted efficiency indicators derived from the first law do not track consistently in magnitude or direction (+ or -) with changes in the second law efficiency. As a result, they are not good indicators of the most effective use of energy resources.

Because our objective is to monitor performance changes of the CHP system over time to detect degradations requiring adjustments to operation, maintenance of equipment, or recommissioning, we choose to track the fuel utilization efficiency of the CHP system and the first law efficiencies and values of effectiveness of individual system components for this purpose. Changes in these metrics will reveal degradations in performance at the system and components levels providing

\footnotetext{
${ }^{8}$ Exergy (or thermodynamic availability) is the resource actually consumed when energy is converted from one form to another, not energy, which is conserved as required by the first law of thermodynamics.

${ }^{9}$ Ertesvag, I.S. and S.J. Nesheim. 2005. "Exergetic Comparison of Energy-Based Efficiency Indicators for Combined Heat and Power (CHP)." In Proceedings of ECOS 2005, Shaping Our Future Energy Systems, The $18^{\text {th }}$ International Conference on Efficiency, Cost, Optimization, Simulation and Environmental Impact of Energy Systems, Signe Kjelstrup and Johan Einar Hustad, editors, Volume I, p. 353. Norwegian University of Science and Technology, Trondheim, Norway. Accessed on the world wide web at http://folk.ntnu.no/ivarse/ecos2005_ertesvag_nesheim.pdf on May 26, 2006.
} 
useful guides for operation and maintenance actions. Moreover, the fuel utilization efficiency and component efficiencies will provide indicators that are directly comparable to benchmarks provided by manufacturers and, therefore, will be of value for verification of commissioning.

Another efficiency measure that captures the value of the energy streams was defined by Horlock $^{10}$, which describes a value-weighted measure of CHP performance, first introduced by Timmermans. ${ }^{11}$ This performance indicator, which they call the "value-weighted energy utilization factor," captures the relative value of the electricity and useful heat production of a CHP system and is defined as

$$
\mathrm{EUF}_{\mathrm{VW}}=\frac{W_{\text {elec }} Y_{\text {elec }}+Q_{\text {th }} Y_{\text {th }}}{Q_{\text {Fuel }} P_{\text {Fuel }}}
$$

where $Y_{\text {elec }}$ and $Y_{\text {th }}$ represent respectively the value per unit of electricity generated (e.g., in $\$ / \mathrm{kWh}$ ) and value per unit of useful heat (or cooling) provided (e.g., in $\$ /$ million Btu), and $P_{F u e l}$ is the price of fuel. By accounting for the value of products, this metric represents the value of products per unit of expenditures on fuel and has units of $\$$ value of produced energy per $\$$ of fuel consumed. In operating a plant, $E U F_{V W}$ should be maximized to achieve the most economic operation. Because generally $Y_{\text {elec }}>Y_{t h}$, a CHP plant should be operated to maximize electricity production. If, however, the amount of electricity above on-site requirements cannot be sold to the grid, the electricity production should follow variations in on-site electric load. Changes in the value of $\mathrm{EUF}_{\mathrm{Vw}}$ caused by degradations in CHP system performance would be weighted by their affect on the value of the energy produced. As a result, faults and performance degradations having the greatest dollar impacts would be recognized by larger changes in the $\mathrm{EUF}_{\mathrm{VW}}$.

Planned future work includes optimization of operations. Although we expect optimization to be driven by the minimization of monetary costs, considerations of the overall system efficiency may be important. If that proves true, recognizing the limitations of first law effeiciencies, we will investigate the potential use of second law efficiencies for that purpose.

\section{Subsystem and Component Efficiencies}

First law efficiencies can be defined for each conversion process or subsystem of the CHP system. These efficiencies enable benchmarking and tracking of the efficiency of individual CHP system components to detect when performance of any of them degrades. For example, for the generic CHP process shown in Figure 1, the electrical generation efficiency $\left(\eta_{E E}\right)$ for a CHP system with a fuel-to-mechanical power prime mover such as a reciprocating engine or micro-turbine would be given by

$$
\eta_{E-\text { Elec }}=\frac{W_{\text {Elec }}}{Q_{\text {Fuel }}},
$$

\footnotetext{
${ }^{10}$ Horlock, J. H. 1997. Cogeneration-Combined Heat and Power (CHP), pp. 26-28. Krieger Publishing Company, Malabar, Florida.

${ }^{11}$ Timmermans, A. R. J. 1978. Combined Cycles and their Possibilities Lecture Series, Combined Cycles for Power Generation. Von Karman Institute for Fluid Dynamics, Rhode Saint Genese, Belgium.
} 
where $\mathrm{W}_{\text {Elec }}$ is the net electrical power output and $Q_{\text {Fuel }}$ is the total rate of input of fuel energy to the prime mover. The efficiency of this subsystem could be subdivided further into the engine efficiency $\left(\eta_{\text {engine }}\right)$ and the generator efficiency $\left(\eta_{\text {generator }}\right)$, where

$$
\eta_{\text {engine }}=\frac{W_{\text {engine }}}{Q_{\text {Fuel }}}
$$

and

$$
\eta_{\text {generator }}=\frac{W_{\text {Elec }}}{W_{\text {engine }}} .
$$

Here, $W_{\text {engine }}$ represents the mechanical shaft power output of the prime mover.

Heat recovery units can be characterized by their effectiveness $\left(\varepsilon_{\mathrm{HRU}}\right)$ which is given by

$$
\varepsilon_{H R U}=\frac{Q_{H R U, \text { actual }}}{Q_{H R U, \text { max }}},
$$

where $Q_{H R U, \text { actual }}$ is the actual total rate of heat transfer from the waste heat stream to the colder fluid as they pass through the heat exchanger, and $Q_{H R U, \max }$ is the maximum possible rate of heat transfer between the two fluids as they passes through the heat recovery unit. A similar general expression would apply for the effectiveness of all other heat exchangers in the system.

Heat recovery units come in two general types: 1) units that transfer sensible heat only to the colder fluid with no change in phase of either fluid (which we will label as heat recover units, HRUs) and 2) heat recovery steam generators (HRSGs), which as their name implies generate steam from liquid water using heat from the waste heat stream (hot exhaust gases from the prime mover in CHP systems).

Because there is only a change in temperature of the two fluids in ordinary HRUs, the actual heat transfer rate is given by

$$
\begin{gathered}
Q_{H R U, \text { actual }}=\left[\dot{v} \rho c_{p}\left(T_{i}-T_{o}\right)\right]_{H R U, \text { HotFluid }} \\
=\left[\dot{v} \rho c_{p}\left(T_{i}-T_{o}\right)\right]_{H R U, \text { ColdFluid }},
\end{gathered}
$$

Where $\dot{v}$ is volumetric flow rate, $\rho$ is density, $c_{p}$ is specific heat at constant pressure, $T_{i}$ is the temperature of the fluid entering the heat recover unit, and $T_{o}$ is the temperature of the fluid exiting the heat recovery unit. The subscripts, HRU,HotFluid and HRU,ColdFluid outside the brackets designate that the expression inside the brackets should be evaluated for the fluids entering the heat recovery unit hot and cold, respectively.

The maximum rate of heat transfer in the heat recovery unit is given by the relation 


$$
Q_{H R U, \text { max }}=\left(\dot{v} \rho c_{p}\right)_{H R U, \text { min }}\left(T_{H R U, \text { HotFluid }, i}-T_{H R U, \text { ColdFluid }, i}\right) .
$$

Here, the subscript $H R U$, min designates that the quantity in parentheses is evaluated for the fluid with the lower value of the product of these three variables. The HRU effectiveness can then be written as

$$
\varepsilon_{\text {HRU }}=\frac{\left(T_{i}-T_{o}\right)_{H R U, \min }}{\left(T_{H R U, H o t F l u i d, i}-T_{H R U, \text { ColdFluid }, i}\right)},
$$

where the subscript HRUmin in the numerator designates that the temperature difference is evaluated for the fluid with the lower value of the product $\dot{v} \rho c_{p}$.

The effectiveness of a heat recovery steam generator $\left(\eta_{\mathrm{HRSG}}\right)$ also can be determined from the general equation for $\varepsilon_{\mathrm{HRU}}$. In this case the actual heat transfer includes the heat of vaporization of the water as well as the sensible heat used to increase its temperature. Therefore, when expressed in terms of the change in the water side, the rate of heat transfer is equal to the difference in enthalpy between the water entering the HRSG and the steam leaving the HRSG, both of the enthalpies being functions of the fluids' temperatures and pressures, i.e.,

$$
Q_{\text {HRSG, actual }}=\dot{v}_{H R S G, w, i} \rho_{H R S G, w, i}\left[h_{s, o}\left(T_{H R S G, o}, P_{H R S G, o}\right)-h_{w, i}\left(T_{H R S G, i}, P_{H R S G, i}\right)\right] \text {, }
$$

under the assumption that the mass flow rate of water input to the HRSG is equal to the mass flow rate of steam output. Here, $h_{s, o}$ is the specific enthalpy of steam leaving the HRSG at temperature $T_{H R S G, o}$ and pressure $P_{H R S G, o}$, and $h_{w, i}$ is the specific enthalpy of the water entering the HRSG at temperature $T_{H R S G, i}$ and pressure $P_{H R S G, i}$. The mass flow rate and density are for water at the inlet to the HRSG.

Alternatively, the rate of heat transfer could be determined for the rate of heat loss from the hot exhaust gas as it passes through the HRSG. In this case, the rate of heat transfer is given by the relation

$$
Q_{H R S G, a c t u a l}=\dot{v}_{H R S G, e x, i} \rho_{H R S G, e x, i} c_{p, e x}\left(T_{H R S G, e, i}-T_{H R S G, e, 0}\right),
$$

where $\dot{v}_{H R S G, e x, i}$ and $\rho_{H R S G, e x, I}$ are respectively the volumetric flow rate and density of exhaust gas coming into the HRSG, $c_{p, e x}$ is the specific heat of the exhaust gas mixture, and $T_{H R S G, e, i}$ and $T_{H R S G, e, o}$ are the temperatures of the exhaust gas streams leaving and coming into the HRSG, respectively.

The maximum possible rate of heat transfer between the two fluids $\left(Q_{H R S G, \max }\right)$ is given by

$$
Q_{H R S G, \max }=\dot{v}_{H R S G, e x, i} \rho_{H R S G, e x, i} c_{p, e x}\left(T_{H R S G, e, i}-T_{H R S G, w, i}\right),
$$

where $T_{H R S G, w, i}$ is the temperature of the saturated water coming into the HRSG. 
Therefore, for an HRSG, the effectiveness can be expressed as ${ }^{12}$

$$
\varepsilon_{H R S G}=\frac{\dot{v}_{H R S G, w, i} \rho_{H R S G, w, i}\left[h_{s, o}\left(T_{H R S G, o}, P_{H R S G, o}\right)-h_{w, i}\left(T_{H R S G, i}, P_{H R S G, i}\right)\right]}{\dot{v}_{H R S G, e x, i} \rho_{H R S G, e x, i} c_{p, e x}\left(T_{H R S G, e, i}-T_{H R S G, w, i}\right)},
$$

or

$$
\varepsilon_{H R S G}=\frac{T_{H R S G, e, i}-T_{H R S G, e, \mathrm{o}}}{T_{H R S G, e, i}-T_{H R S G, w, i}}
$$

HRSGs often have stages, which produce steam at different pressures (e.g., high-pressure steam, medium pressure steam, and low pressure steam). In theses cases, the enthalpy difference of each output stream must be considered separated, so that

$Q_{H R S G, a c t u a l}=\sum_{j}\left[\dot{v}_{H R S G, s, o} \rho_{H R S G, s, o} h_{s, o, i}\left(T_{H R S G, o}, P_{H R S G, o}\right)\right]_{j}-\dot{v}_{H R S G, w, i} \rho_{H R S G, w, i} h_{w, i}\left(T_{H R S G, i}, P_{H R S G, i}\right)$,

and

$$
\varepsilon_{H R S G}=\frac{\sum_{j}\left[\dot{v}_{H R S G, s, o} \rho_{H R S G, s, o} h_{s, o, i}\left(T_{H R S G, o}, P_{H R S G, o}\right)\right] \dot{v}_{j} \dot{j}_{H R G, w, i} \rho_{H R S G, w, i} h_{w, i}\left(T_{H R S G, i}, P_{H R S G, i}\right)}{\dot{v}_{H R S G, e x, i} \rho_{H R S G, e x, i} c_{p, e x}\left(T_{H R S G, e, i}-T_{H R S G, w, i}\right)},
$$

Here, the summation in the numerator is over all HRSG stages of steam production with the flow rate, density and enthalpy for each stage corresponding to the conditions (e.g., temperature and pressure) of the steam flow exiting the $j$ th stage of the HRSG. If energy losses from the HRSG are negligible and essentially all of the energy transferred from the exhaust gas is used to produce steam, the effectiveness of the HRSG can still be determined from the relation

$$
\varepsilon_{H R S G}=\frac{T_{H R S G, e, i}-T_{H R S G, e, \mathrm{o}}}{T_{H R S G, e, i}-T_{H R S G, w, i}},
$$

The efficiency of absorption chillers is given by the coefficient of performance ( $\left.C O P_{A b C h i l l e r}\right)$ defined as

$$
C O P_{\text {AbChiller }}=\frac{Q_{\text {evap }}}{Q_{\text {regen }}}
$$

${ }^{12}$ Assuming that $\left(\dot{v} \rho c_{p}\right)_{\mathrm{ex}, \mathrm{i}}<\left(\dot{v} \rho c_{p}\right)_{\mathrm{w}, \mathrm{i}}$. 
where $Q_{\text {evap }}$ is the rate of heat loss from returned chilled water passing through the evaporator and $Q_{\text {regen }}$ is the rate of heat loss from the steam or hot water as it passes through the absorption unit's desorber ${ }^{13}$ to drive the working fluid from solution.

Electric chillers operate on the vapor compression cycle using electric motors to drive compressors. The efficiency of these units is given by the vapor compression cycle coefficient of performance defined as

$$
C O P_{\text {Chiller }}=\frac{Q_{\text {evap }}}{W_{\text {ChillerElec }}}
$$

where $Q_{\text {evap }}$ as with the absorption chiller represents the rate of heat loss as cooling water passes through the evaporator reducing its temperature and $W_{\text {ChillerElec }}$ is the electric power input to the chiller.

Another component of a CHP system with a chiller is the cooling tower, which is used to reject the heat gained when the refrigerant vapor is condensed into liquid. The cooling tower uses evaporative cooling to reject heat from the condensate and its efficiency is defined as:

$$
\eta_{C T}=\frac{\left(T_{C T, w . i}-T_{C T, w, o}\right)}{\left(T_{C T, w, i}-T_{w b}\right)},
$$

where, $\eta_{\mathrm{CT}}$ is cooling tower efficiency, $T_{C T, w, i}$ is the inlet temperature of the warm water to the tower, $T_{\mathrm{CT}, \mathrm{w}, \mathrm{o}}$ is the outlet temperature of cooled water from the tower and $T_{w b}$ is the wet-bulb temperature of the ambient air to which heat is rejected by the cooling tower. All temperatures are either in ${ }^{\circ} \mathrm{C}$ or ${ }^{\circ} \mathrm{F}$.

The value of $\eta_{\text {ст }}$ only indicates how well the cooling tower cools the condenser water and how close the water temperature approaches the limiting wet-bulb temperature of the ambient air. It does not indicate how the cooling was achieved or how much external electrical energy input was used to achieve this reduction in temperature. For example, if the cooling tower medium becomes fouled, increasing resistance to air flow and inhibiting heat transfer, the cooling tower fans might run longer or at a higher speed (for variable speed fans) to achieve the same temperature drop for the water that was accomplished with less fan energy when the medium was not fouled. In addition electric power is used to pump the condenser water to and from the cooling tower. To provide a metric for how efficiently electricity is used in this process, we define a cooling tower electric utilization efficiency $\left(\eta_{\mathrm{CT}, \mathrm{elec}}\right)$ as

$$
\eta_{C T, \text { Elec }}=\frac{Q_{C T, t h}}{W_{C T, \text { elec }}},
$$

\footnotetext{
${ }^{13}$ Often referred to as a "generator." We use the term "desorber" to emphasize this unit's function and to prevent confusion with electric generators identified throughout this document.
} 
where $Q_{C T, t h}$ is the rate of heat loss by the condenser water from passing through the cooling tower and $W_{C T, \text { elec }}$ is the electric power use by the cooling tower fans and pumps. The electric power use is the sum of the electric power used by the individual pumps and fans, i.e.,

$$
W_{C T, e l e c}=\sum_{j} W_{C T, e l e c, j},
$$

where $W_{C T, e l e c, j}$ is the electric power use by the $j t h$ pump or fan and the summation is over all pumps and fans.

Some CHP applications use desiccant systems for dehumidification. The efficiency of the desiccant system $\left(\eta_{D}\right)$ is defined as the ratio of dehumidification load (rate of moisture removal) to the rate of heat input for regenerating the desiccant:

$$
\eta_{D}=\frac{Q_{d}}{Q_{d, \text { input }}},
$$

where, $Q_{d}$ is the dehumidification load and the $Q_{d, \text { input }}$ is the rate at which heat is used to regenerate the desiccant.

Pumps and fans represent ancillary equipment for moving liquids and air by imparting a pressure difference to them. The efficiency of a pump $\left(\eta_{P}\right)$ can be expressed as

$$
\eta_{\text {Pump }}=\frac{W_{\text {Pump }}}{W_{\text {Pump ,elec }}},
$$

where $W_{\text {Pump }}$ is the mechanical power output imparted by the pump to the liquid, and $W_{\text {Pumpelec }}$ is the electric power input to the pump motor. The mechanical power imparted by the pump to the liquid is equal to the product of the mass flow rate through the pump and the pressure difference across the pump, i.e.,

$$
W_{\text {Pump }}=\dot{v}_{\text {Pump }}\left(P_{\text {discharge }}-P_{\text {suction }}\right),
$$

where $\dot{v}_{\text {Pump }}$ is the volumetric flow rate through the pump, $P$ represents pressure, and the subscripts discharge and suction identify variables at the pump suction port (inlet) and discharge port (outlet). The difference between the discharge and suction pressures is the pressure head for the pump.

Fan efficiency $\left(\eta_{F a n}\right)$ is given by the relation

$$
\eta_{\text {Fan }}=\frac{W_{\text {Fan }}}{W_{\text {Fan,elec }}},
$$


where $W_{F a n}$ is the useful power output from the fan to the air, and $W_{\text {Fan,elec }}$ is the electric power input to the fan motor. The useful power output is equal to the product of the volumetric flow rate through the fan and the pressure increase across the fan, ${ }^{14}$ i.e.,

$$
W_{\text {Fan }}=\dot{v}_{\text {Fan }}\left(P_{\text {outlet }}-P_{\text {inlet }}\right) \text {, }
$$

where $P_{\text {outlet }}$ and $P_{\text {inlet }}$ are the pressures immediately upstream and downstream of the fan, respectively, and $\dot{v}_{\text {Fan }}$ is the volumetric flow rate through the fan. For both pumps and fans, the equations given represent the efficiencies for the pump-motor and fan-motor combinations rather then the mechanical devices alone.

We propose to use a combination of the overall CHP fuel utilization efficiency and the efficiencies of the individual components and subsystems of CHP systems as metrics for monitoring and tracking CHP efficiency. During development of algorithms for the specific types of CHP systems selected for capabilities development in this project, the various rates of heat gain and heat loss appearing in the expressions for the component efficiencies will be expanded and sensor requirements for measurements identified.

\footnotetext{
${ }^{14}$ The efficiency obtained depends on whether the difference in total pressure or the difference in static pressure is used as this pressure difference. Both are valid and can be used as indicators of degradation in fan performance over time.
} 


\section{CHP Use in United States}

This section provides an overview of existing commercial building sites in the U.S. having integrated CHP systems. The information presented is drawn largely from the 2003 study of the market potential for thermally-activated CHP by Energy and Environmental Analysis, Inc. $(2003)^{15}$, which represents the most comprehensive characterization of the CHP market currently available. The database upon which that study is based is somewhat incomplete in its coverage of CHP systems of less than $1 \mathrm{MW}$ capacity. As a result, the number of sites reported is likely low, but the total capacities reported are likely affected little because of the dominance of large sites on total capacity ${ }^{15}$.

Total U.S. CHP capacity in 2000 was 508 MW installed across 318 sites. Most of these sites were concentrated in five states with $42 \%$ in California and another $36 \%$ located in New York, New Jersey, Connecticut, and Massachusetts, where electricity prices tend to be high. The average site size is $1601 \mathrm{~kW}$, which is somewhat misleading because of the significant influence of a small number of large sites, while the median site capacity is only $150 \mathrm{~kW} .^{15}$

When divided by market segment, the greatest number of sites and largest percentage of total CHP capacity by far are in healthcare facilities $(64.2 \%$ of installations and $92.3 \%$ of capacity; see Figure 3 and Figure 4 ) followed by lodging (26.4\% and 6.0\%, respectively). The other sectors together represent less than $10 \%$ of the total installations and less than $2 \%$ of total capacity. ${ }^{15}$

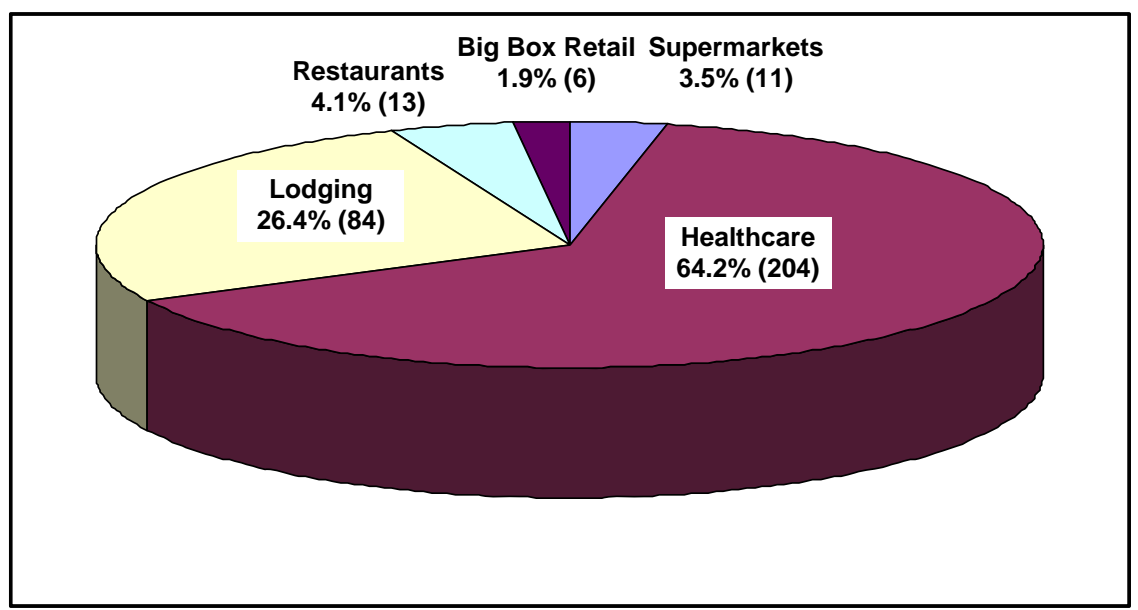

Figure 3. Distribution of U.S. CHP sites by market segment. Numbers in parentheses represent the actual number of $\mathrm{CHP}$ sites.

\footnotetext{
${ }^{15}$ Energy and Environmental Analysis, Inc (EEA). 2003. Market Potential for Advanced Thermally Activated BCHP in Five National Account Sectors. Oak Ridge National Laboratory, Washington, DC.
} 


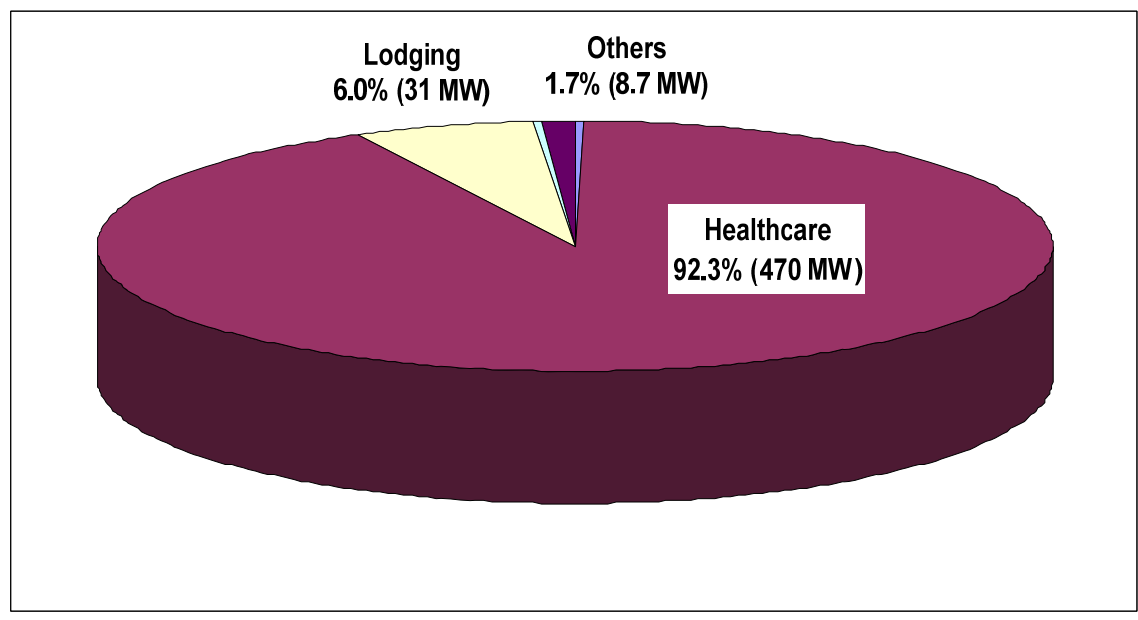

Figure 4. Distribution of U.S. CHP Capacity by Market Segment. Numbers in parentheses identify the actual total installed capacity for each sector.

CHP installations at healthcare facilities have the largest capacities on average, with an average site capacity of $2,302 \mathrm{~kW}$. This average is dominated by seven large hospitals, which together represent over $50 \%$ of the total capacity of this market segment. The median site capacity of the healthcare sector is $230 \mathrm{~kW}$, which is second in median site size to the big box retail segment for which the median site capacity is $363 \mathrm{~kW}$ (and average site capacity is $994 \mathrm{~kW}$ ). Restaurants have the smallest capacity with an average of $96 \mathrm{~kW}$ and a median of $23 \mathrm{~kW} .{ }^{15}$

Natural gas fuels approximately $83 \%$ of the CHP capacity. Interestingly, wood and wastes represent the fuel for $11 \%$ of the capacity, followed by oil and coal, which provide fuel for $4 \%$ and $2 \%$ of the total capacity, respectively.

Figure 5 and Figure 6 show the number of U.S. integrated CHP sites and total capacity, respectively, by type of prime mover. Reciprocating engines are used in $84 \%$ of the sites, yet provide only $24 \%$ of the total capacity, indicating that they are common in smaller integrated CHP applications. In contrast, although combined cycles are used in just over $2 \%$ of the sites, they provide nearly $43 \%$ of total capacity in much larger units. Combustion turbines and boiler/steam turbines make substantial contributions to total capacity, representing $17.7 \%$ and $15.1 \%$, respectively, yet together are used at a total of only $13.2 \%$ of the sites.

Combined heat and power represents $4.3 \%(41 \mathrm{GW})$ of U.S. electricity generation capacity and produced $5.1 \%$ of total electricity generated in $2005 .{ }^{16}$ This capacity and production was from plants dedicated to selling electric power and heat to the public. The contribution of integrated CHP to this total is very small $(0.05 \%)$.

Compared to European countries, the U.S. use of CHP is towards the low end (see Figure 7). CHP provides about $40 \%$ of the electric power in Denmark, followed by $30 \%$ for the Netherlands. The U.S. at 5.1\% exceeds the CHP contribution of the U.K. and France, however.

\footnotetext{
${ }^{16}$ Energy Information Administration (EIA). 2006. Annual Energy Outlook 2006 with Projections to 2030. Report \#DOE/EIA-0383(2006). U.S. Energy Information Administration, Washington, DC.
} 


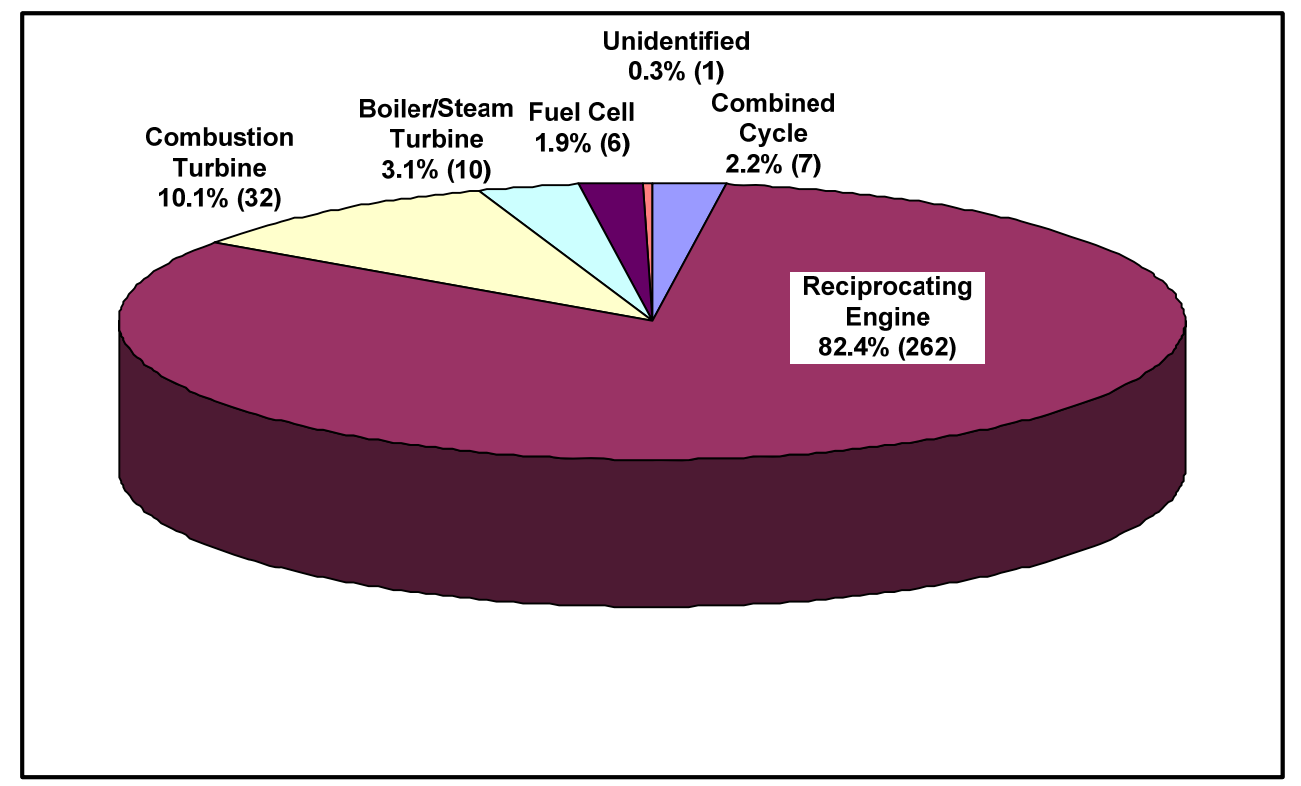

Figure 5. Fraction of U.S. Integrated CHP sites by Type of Prime Mover. Numbers in parentheses are the number of sites for each type of prime mover.

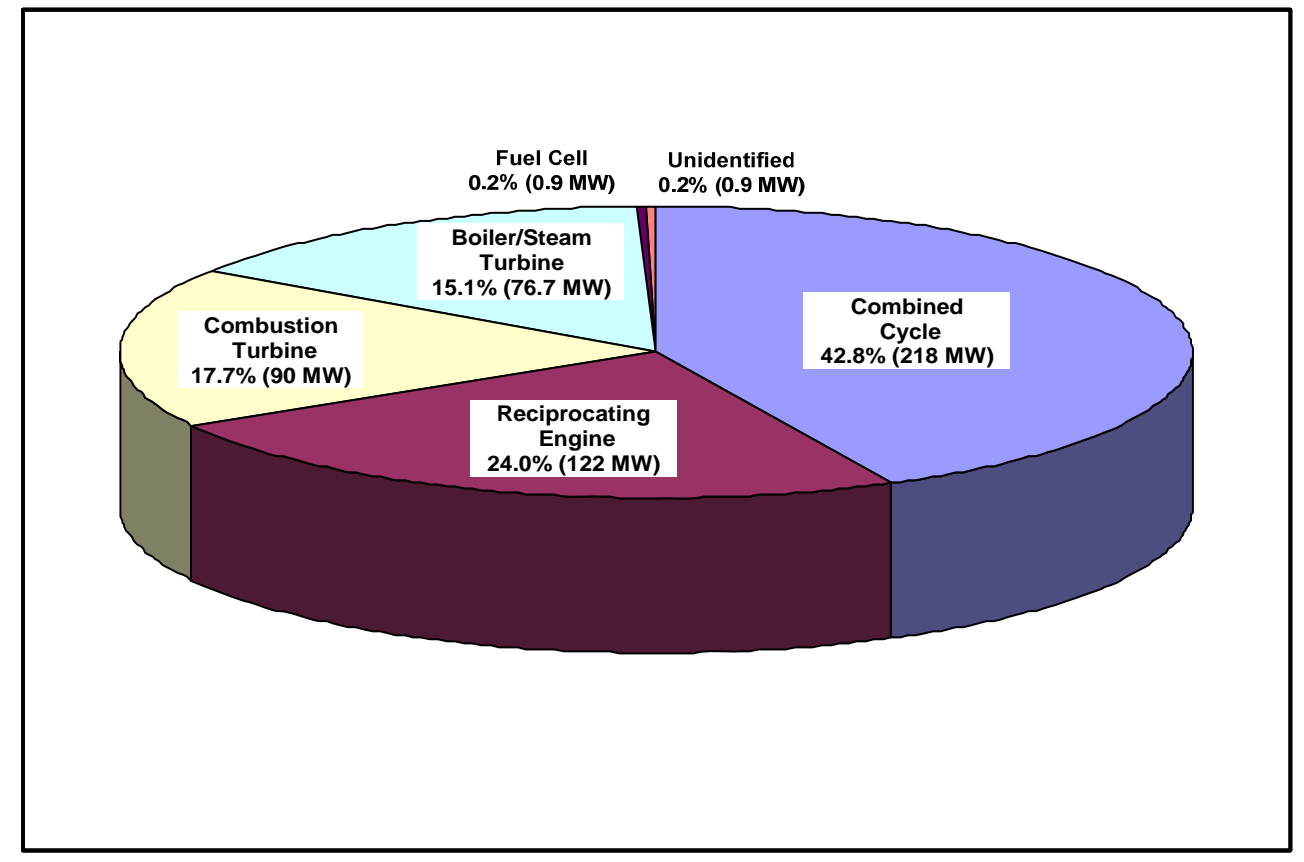

Figure 6. Fraction of U.S. Integrated CHP Capacity by Type of Prime Mover. Numbers in parentheses are the total capacities for each type of prime mover. 


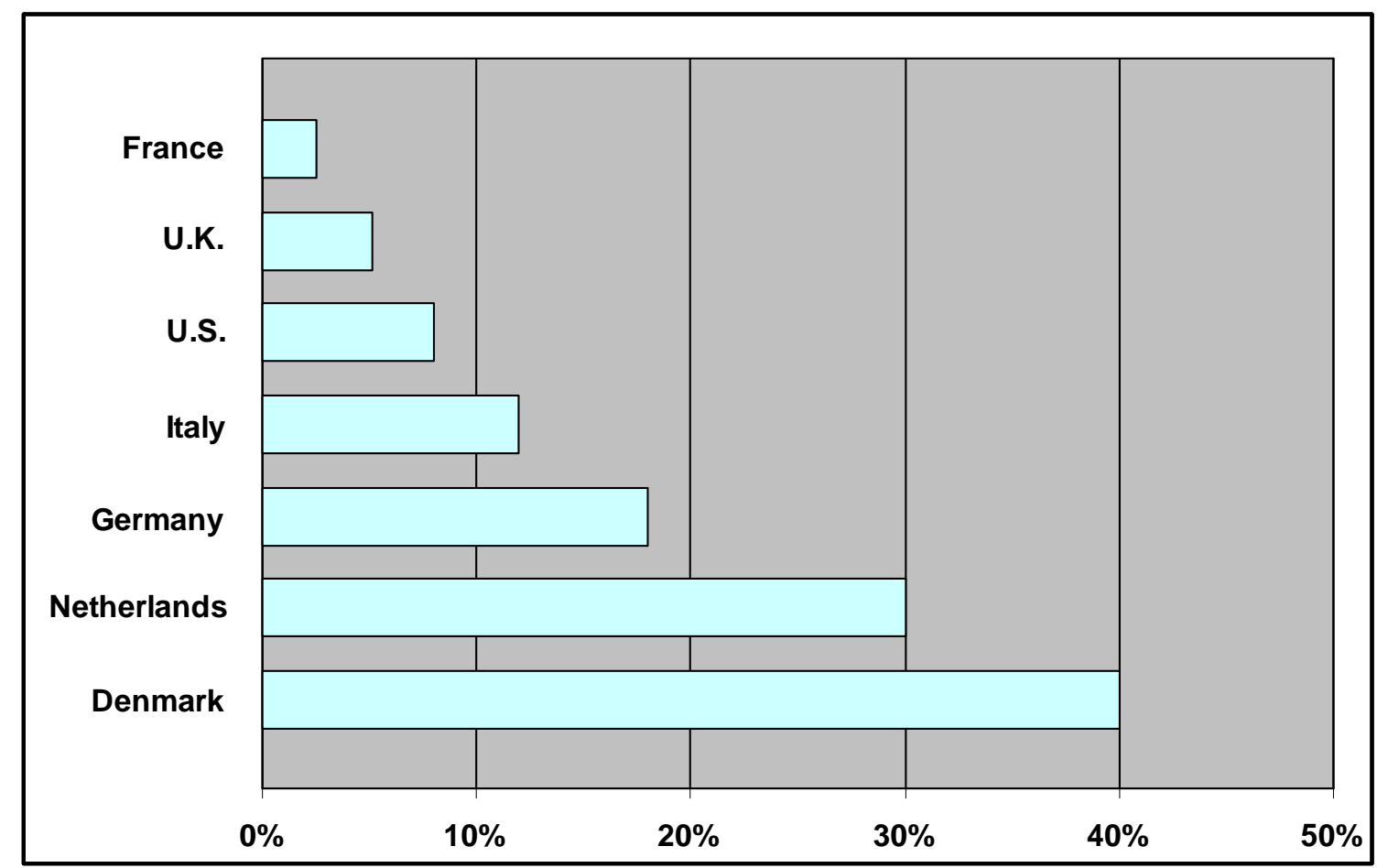

Figure 7. The Portion of National Power Production from CHP for Select European Countries and the U.S. in 1997. ${ }^{17}$

${ }^{17}$ R. Hite. 2001. "Combined Heat and Power." Presentation to the American Society of Heating, Refrigerating, and Air-Conditioning Engineers, Santa Ana, California, October 23, 2001. Energy Nexus Group, Carlsbad, CA. 


\section{Distributed Energy and Combined Cooling, Heating and Power Technologies}

A CHP system is generally integrated using two or more individual components including a prime mover (heat engines) with a generator or fuel cells, heat exchanger for heat recovery, and thermally activated cooling and dehumidification technologies. These components are integrated as a single unit with electrical and mechanical connections. The identity of CHP is primarily driven by the type of power generator equipment used because it dictates which thermally activated technologies can use the waste heat. Although there are several different ways to categorize components of the CHP system, the most commonly used categorization is to separate the power generation technologies from the thermal technologies (Figure 8).

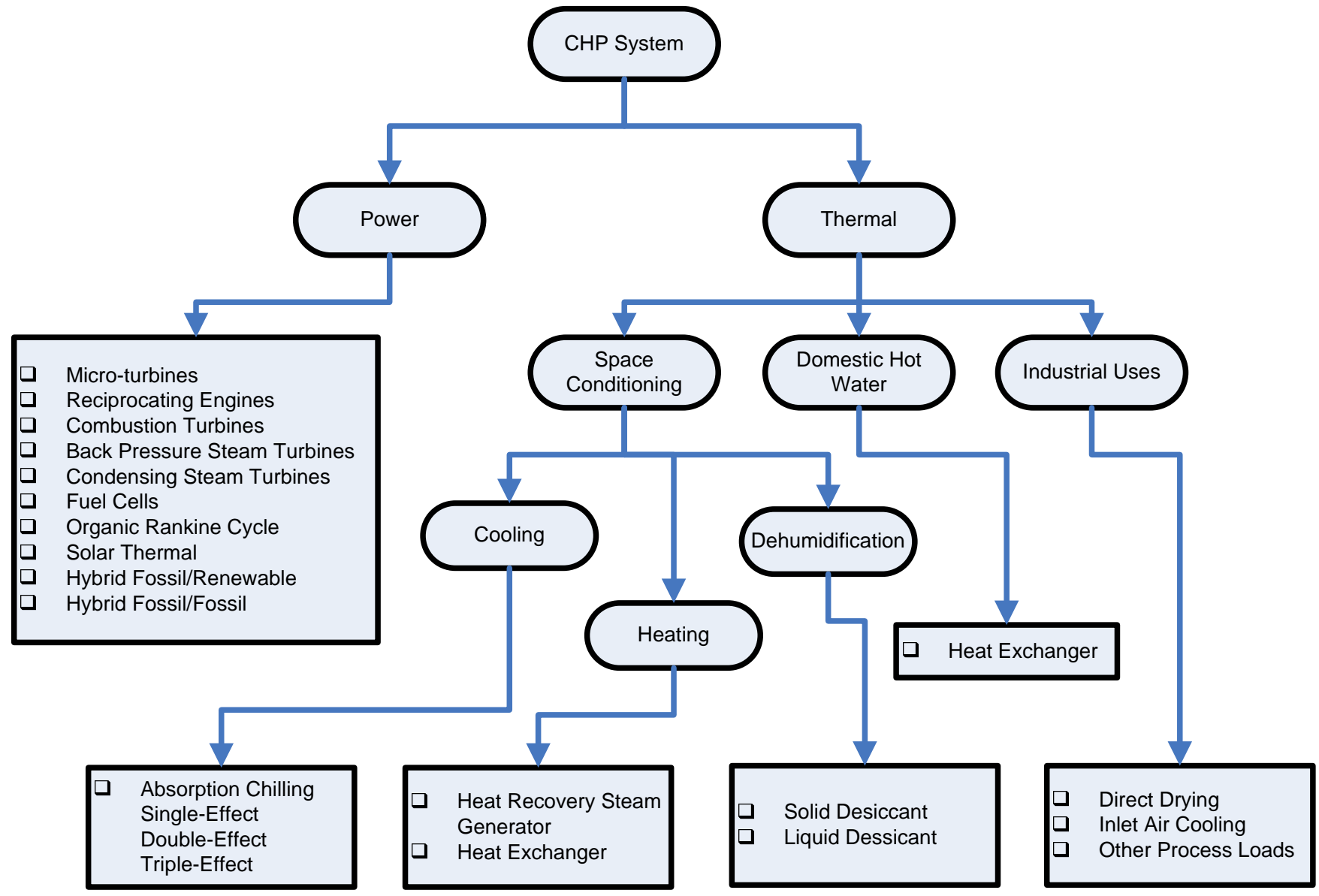

Figure 8 - Schematic of CHP Component Categorizations (the ovals in the schematic represent a process and rectangles represent technologies or applications)

\section{Power Generation Systems}

Most CHP systems use prime movers to generate electricity. Most prime movers directly convert some form of fuel energy into mechanical shaft power, which drives a generator to produce electricity. Fuel cells are an exception because they covert fuel energy directly to 
electricity through an electro-chemical process. The power generation technologies include: micro-turbines, reciprocating engines, combustion turbines, back pressure steam turbines, and condensing steam turbines, all powering an electric generator, as well as fuel cells, organic Rankine cycles with an appropriate turbine/generator, solar thermal energy conversion with a steam turbine/generator, and/or hybrid systems. Most small to medium ( $<1 \mathrm{MW}) \mathrm{CHP}$ systems use micro-turbine and reciprocating engine technologies to generate power. For detailed descriptions of the various power technologies, please refer to MAC $2003^{4}$.

\section{Thermal Technologies}

Thermal technologies used in CHP systems can be classified into three broad groups based on the application: 1) space conditioning, 2) domestic hot water or process heat, and 3) other industrial uses. Space conditioning can be further divided into three groups: 1) cooling, 2) heating, and 3) dehumidification.

The cooling technologies that are used in CHP systems are absorption chillers. While absorption heat pumps can be used for space heating, they are not currently used in CHP systems. Most CHP systems use hot water or steam generated in the heat recovery system directly for space heating. The dehumidification systems are either solid or liquid desiccant-based, with waste heat used for regeneration of the desiccant materials. Detailed descriptions of the various thermally activated technologies can be found in MAC $2003^{4}$. 


\section{CHP Configurations}

In this section, some common configurations of CHP systems that have been installed in the U.S are described. It is important to look at the common CHP configurations because they will form the basis for the system level algorithms to be developed in this project. Algorithms will not be developed in this project for all configurations because of resource constraints.

A simple CHP system configuration is shown in Figure 9; it consists of a reciprocating engine (or fuel cell) with jacket heat recovery. Because the quality of hot water produced is low $\left(180^{\circ} \mathrm{F}\right)$ for CHP systems with reciprocating engines and some fuel cell technologies, the waste heat utilization is strictly limited to domestic hot water or low grade process heat. The configuration is most suitable for applications where power and domestic hot water is needed (for example, a commercial building).

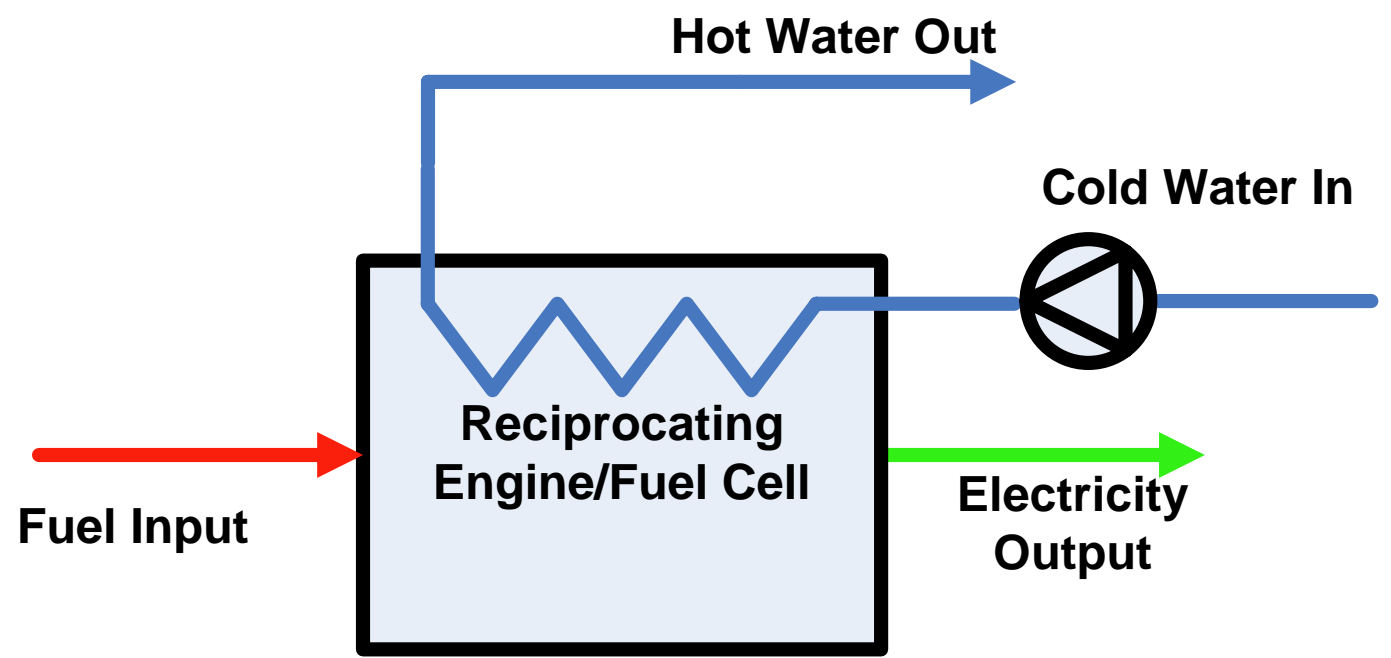

Figure 9 - Power Generation Using a Reciprocating Engine Generator or Fuel Cell with Hot Water Recovery

Figure 10 shows a CHP system that also uses a reciprocating engine but has both jacket heat and exhaust heat recovery The higher quality of heat recovered in this configuration allows for either hot water production or generation of low grade steam (e.g., at 15 psig). In some cases, additional fuel is used in a duct burner to provide supplemental heat for producing additional hot water or steam to meet thermal demands. This configuration is suitable for applications where power and low-grade process heat can be used (for example, industrial, agricultural or commercial building sectors). 


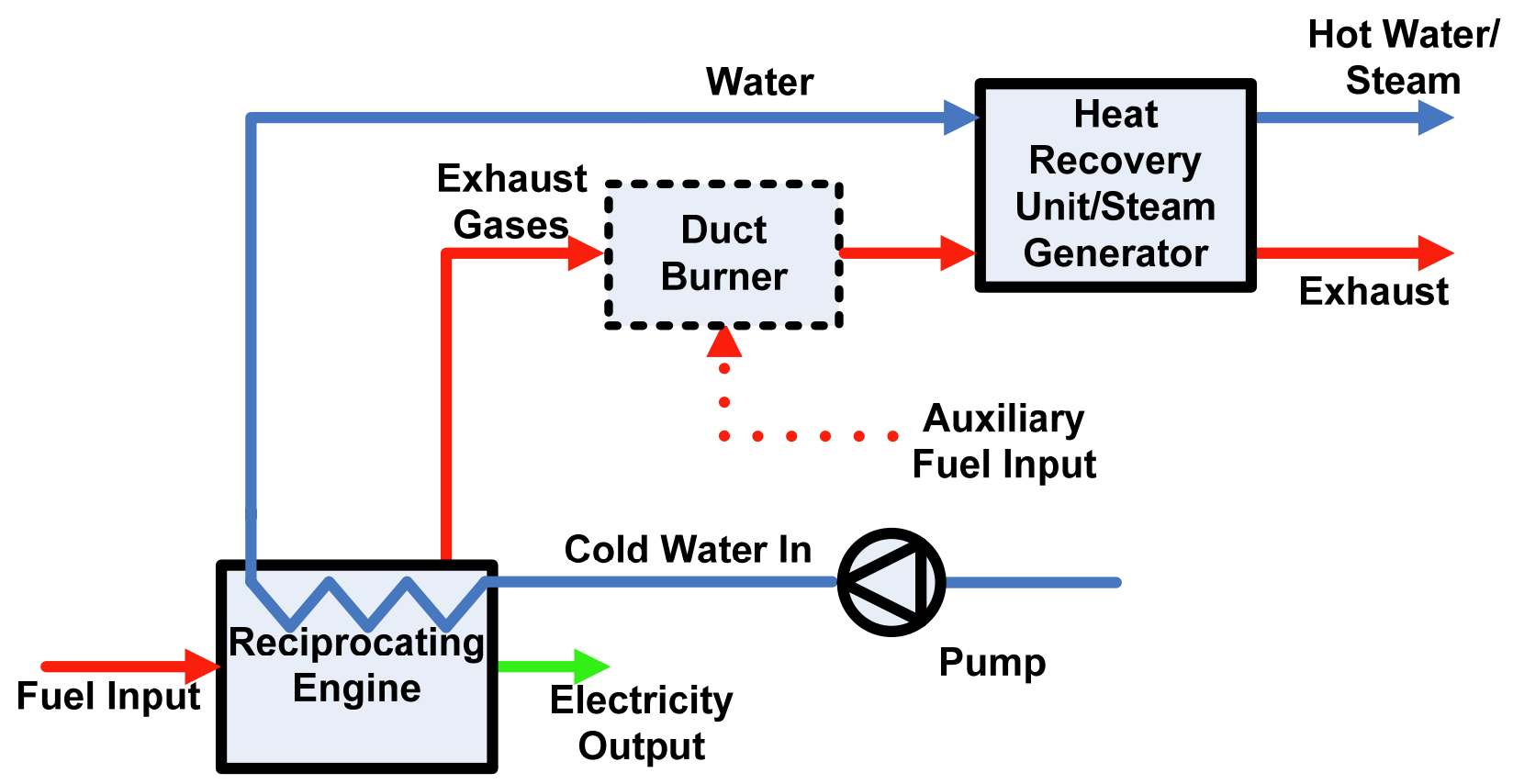

Figure 10 - Reciprocating Engine Generator with Jacket and Exhaust Heat Recovery

The next configuration shows a micro-turbine with an exhaust heat recovery system (Figure 11). In most cases, the waste heat recovered from the exhaust is used to generate hot water, which can be used as domestic hot water or used for process applications. Alternatively, the system can be designed to produce steam or hot air. Additional fuel can be used in the heat recovery system to augment hot air, hot water or steam production to meet additional needs. This configuration is most suited and, therefore, commonly used in the commercial and institutional buildings sector.

The configuration shown in Figure 12 uses a micro-turbine with exhaust heat recovery, a hot water-fired or steam-fired absorption chiller, ${ }^{18}$ and a cooling tower. This configuration is commonly used in commercial building applications. In most cases, the absorption system is limited to single-effect lithium bromide and water. Auxiliary fuel can be burned in a duct burner to meet additional thermal demand. This configuration is most suited for commercial and institutional buildings and is commonly used in such buildings.

\footnotetext{
${ }^{18}$ Absorption systems can be used for both heating and cooling, like heat pumps. Most CHP installations that we reviewed did not have a heat pump absorption system.
} 


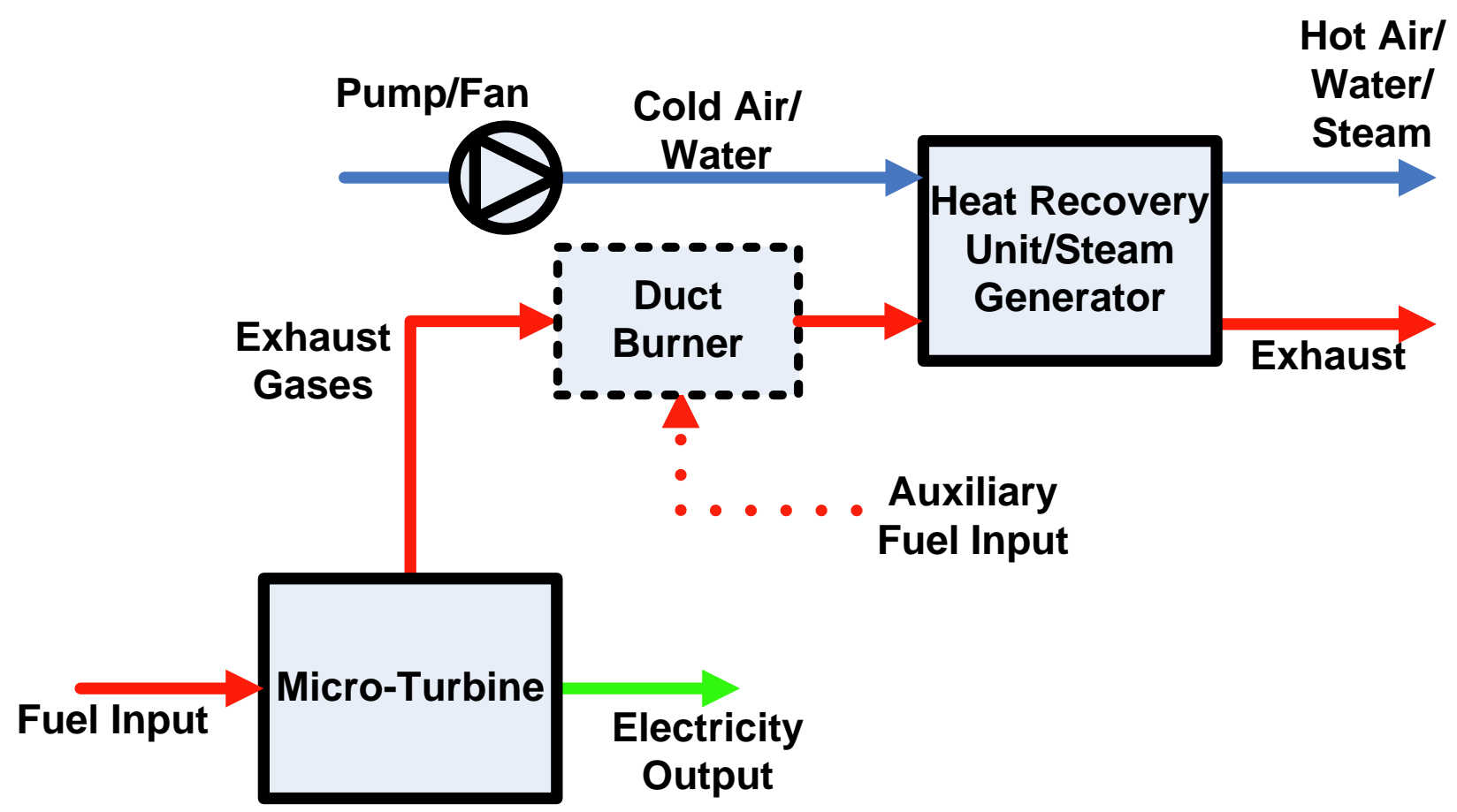

Figure 11 - Micro-Turbine Generator with Exhaust Heat Recovery System

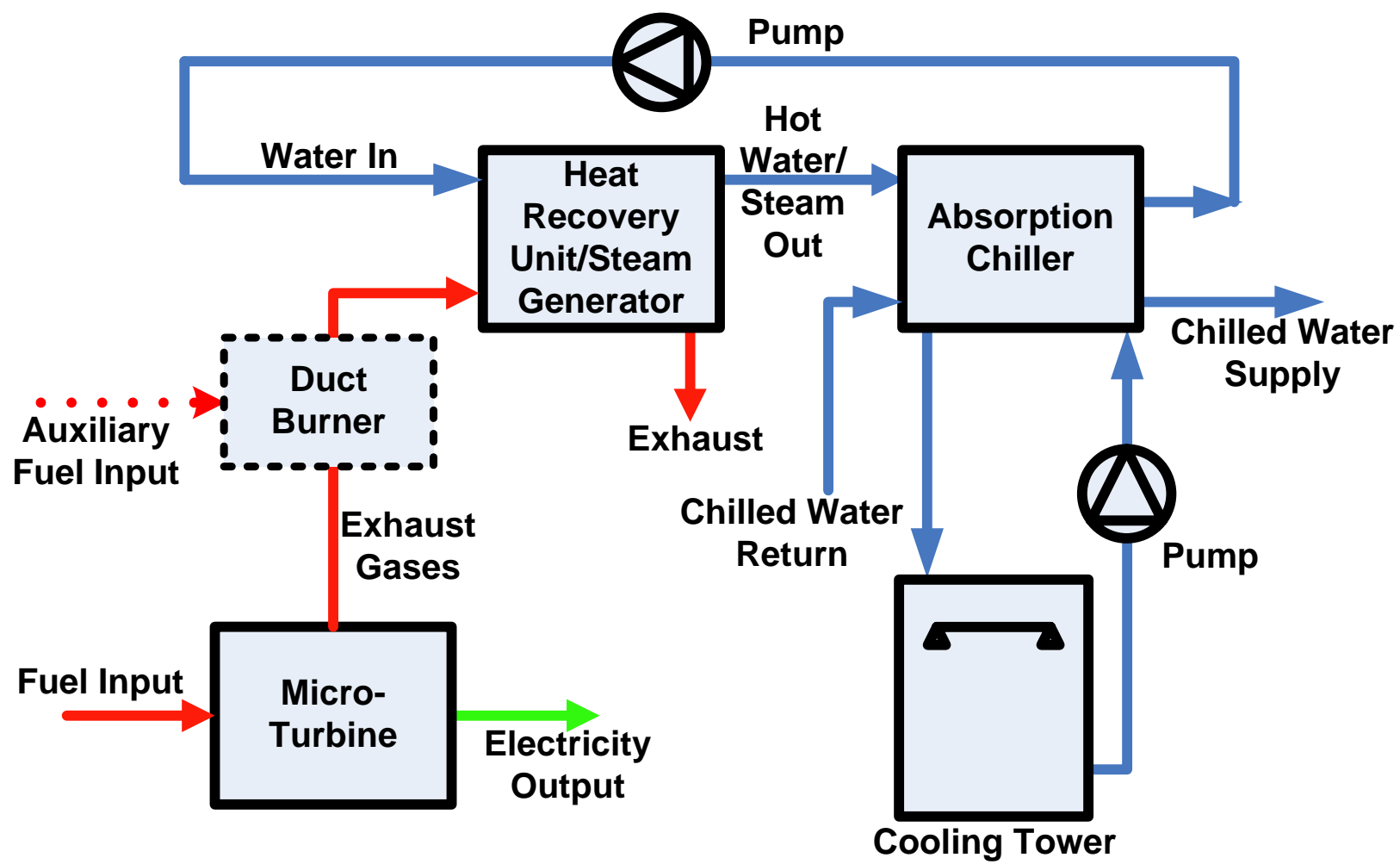

Figure 12 - Micro-Turbine Generator with Exhaust Heat Recovery and Absorption Chiller with a Cooling Tower 
Figure 13 shows a configuration using a micro-turbine with a direct-fired ${ }^{19}$ absorption chiller having a cooling tower for heat rejection and a desiccant system for dehumidification of air. This configuration is commonly used in commercial buildings applications. Because waste heat is used directly in the absorption chiller, double- and triple-effect absorption systems (either lithium-bromide/water or water/ammonia) can be used. In addition to an absorption chiller, the configuration also shows a desiccant dehumidification system to dehumidify the conditioned air. Additional fuel can be used to supplement waste heat recovery to increase the chiller or dehumidification capacities.

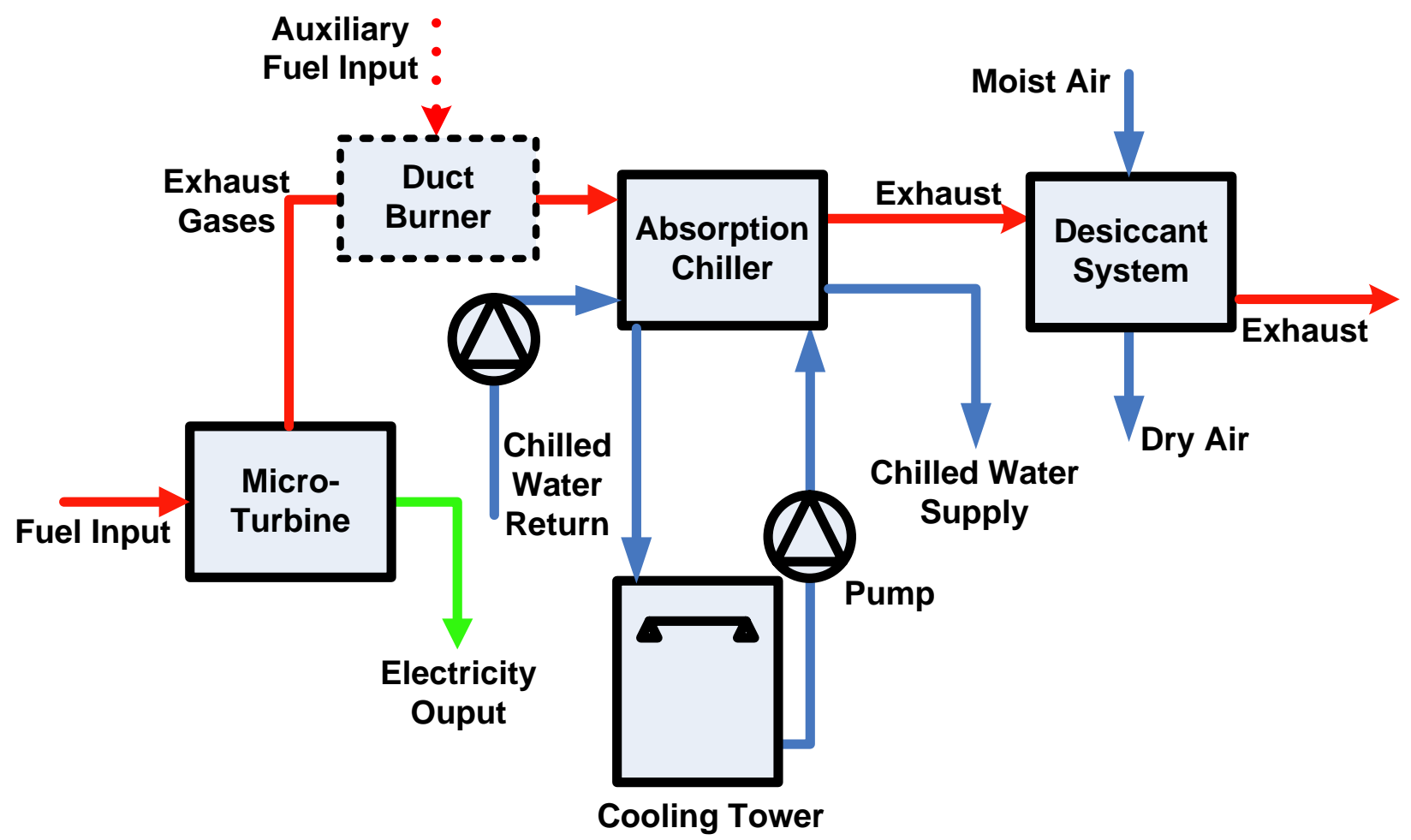

Figure 13 - Micro-Turbine Generator with Direct-Fired Absorption Chiller using a Cooling Tower and Desiccant System

Figure 14 shows a configuration with a micro-turbine (or a reciprocating engine with no jacket heat recovery shown), heat-recovery heat exchanger or steam generator, hot-water- or steamfired absorption chiller with cooling tower and a desiccant system that is direct-fired. To increase the cooling or dehumidification capacity, additional fuel can be used to supplement waste heat recovered from the prime mover to produce more hot water or steam. The configuration is most suited for commercial buildings with significant latent loads - buildings such as restaurants, assemblies, and schools.

Figure 15 shows a configuration with a fuel cell (including a reformer), hot-water-fired absorption chiller with cooling tower and hot-water-fired desiccant system. Currently, this configuration is not commonly used, but is most suited for commercial building applications.

\footnotetext{
${ }^{19}$ Direct-fired implies that the waste heat is directly used for regeneration in the absorption chiller.
} 


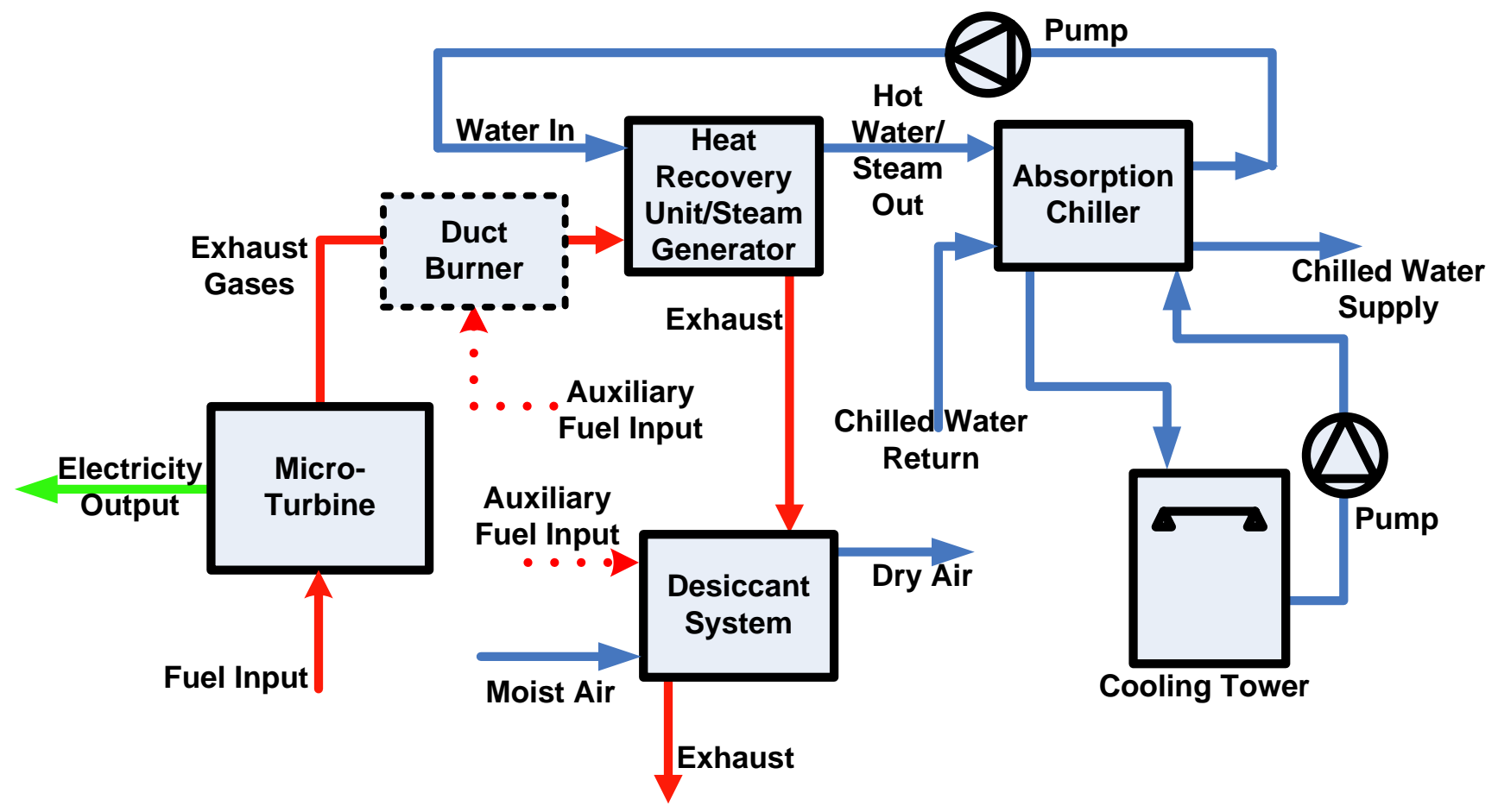

Figure 14 -- Micro-Turbine Generator with Heat Recovery Heat Exchanger, Hot-Water- or Steam-Fired Absorption Chiller with a Cooling Tower and Direct-Fired Desiccant System 


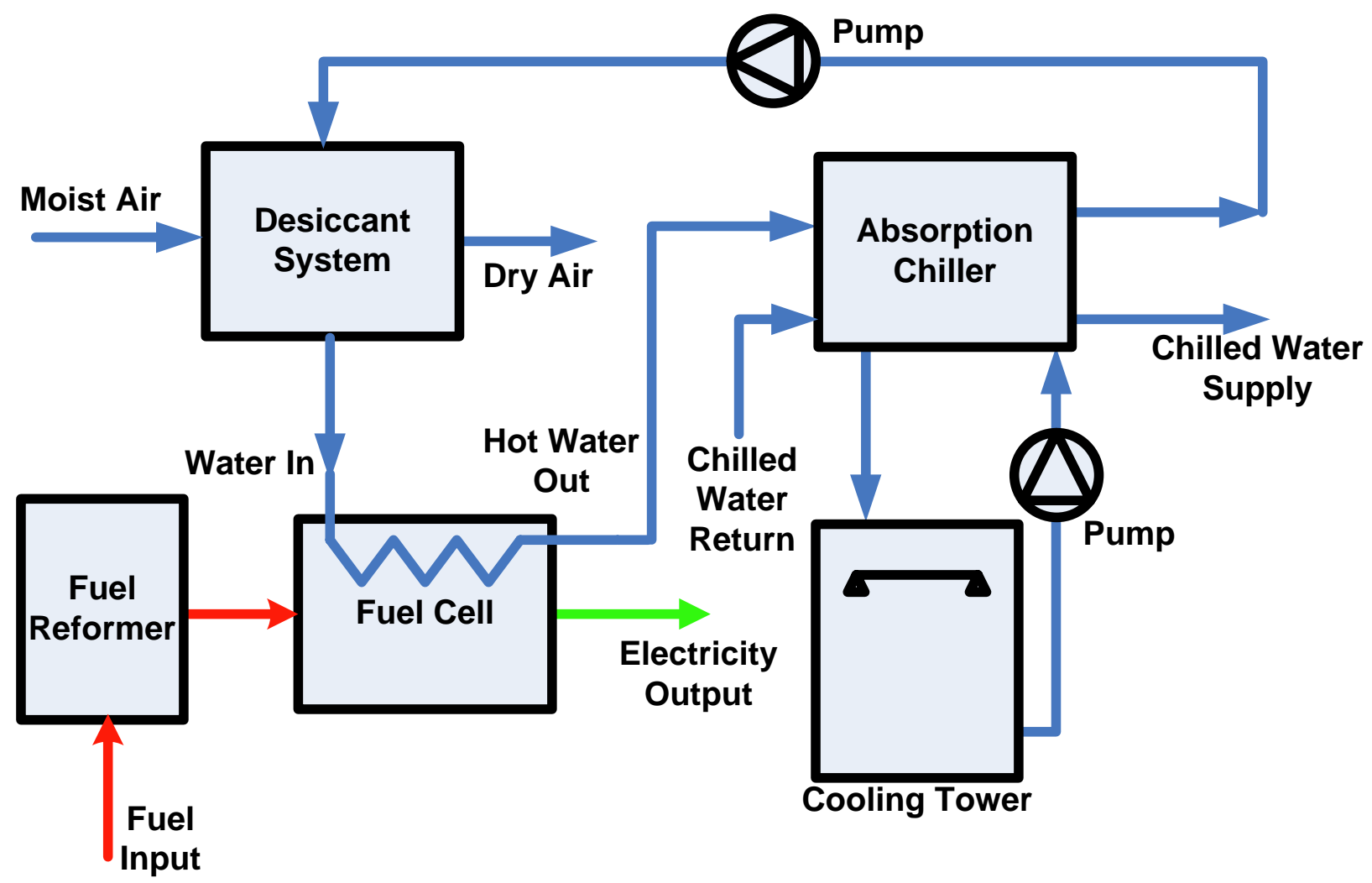

Figure 15 - Fuel Cell with Hot Water-Fired Absorption Chiller with a Cooling Tower and Hot-Water-Fired Desiccant System

Figure 16 shows a boiler that generates steam to run a backpressure steam turbine, electric generator and steam-fired absorption chiller with a cooling tower. Figure 17 shows a boiler that generates steam to run an extraction steam turbine with a condenser, electric generator and steam-fired absorption chiller. These configurations are commonly used in industrial facilities and are typically over $1 \mathrm{MW}$ in generation capacity.

Figure 18 shows a combined-cycle CHP system that has a gas turbine with generator, heat recovery steam generator, backpressure steam turbine with generator, and steam-fired absorption chiller with cooling tower. This configuration is typically used in large industrial facilities and is usually several megawatts in electric generation capacity. 


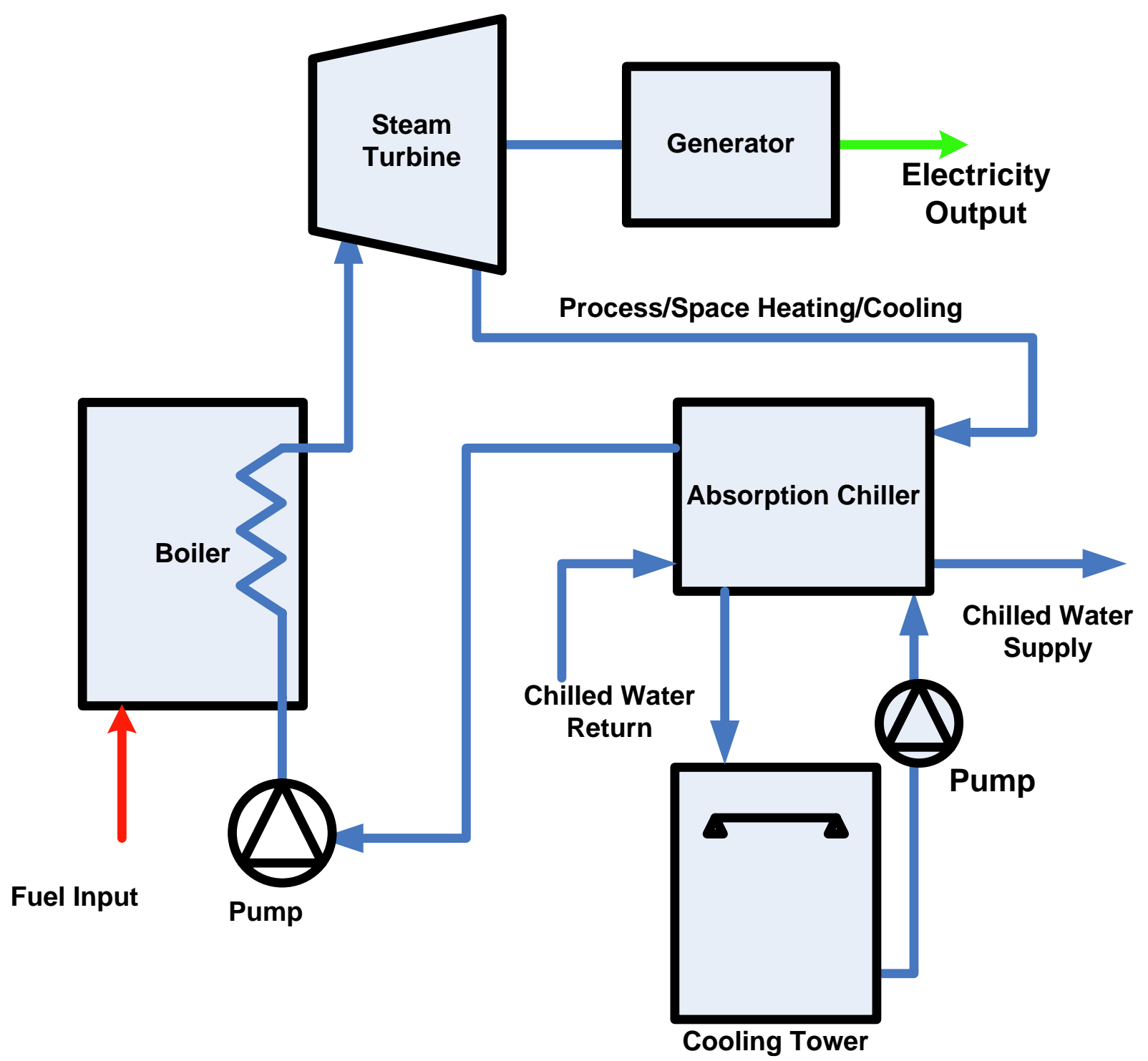

Figure 16 - Backpressure Steam Turbine with a Boiler, Generator, and Steam-Fired Absorption Chiller with Cooling Tower 


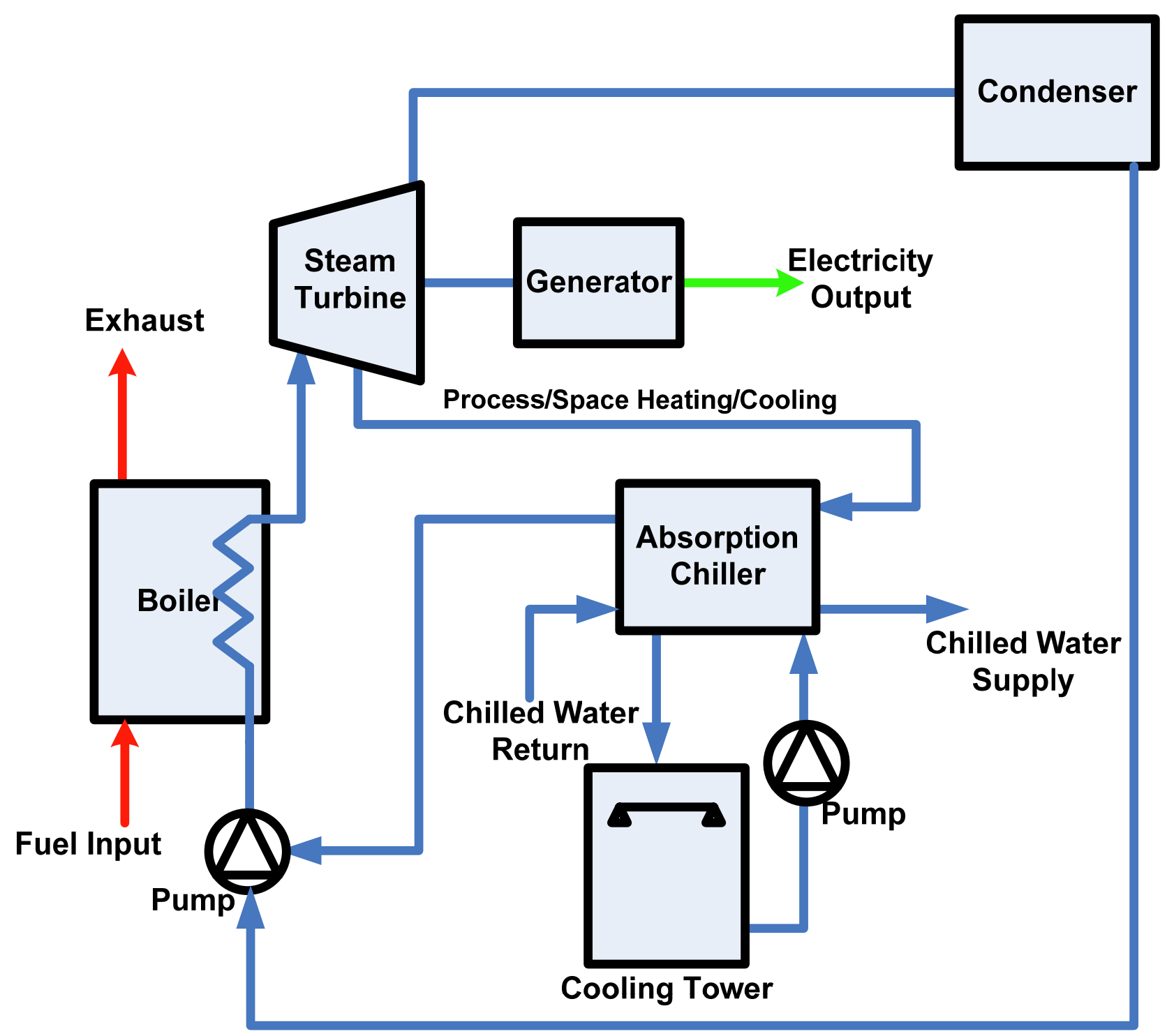

Figure 17 - Extraction Steam Turbine with a Boiler, Generator, and Steam-Fired Absorption Chiller with Cooling Tower 


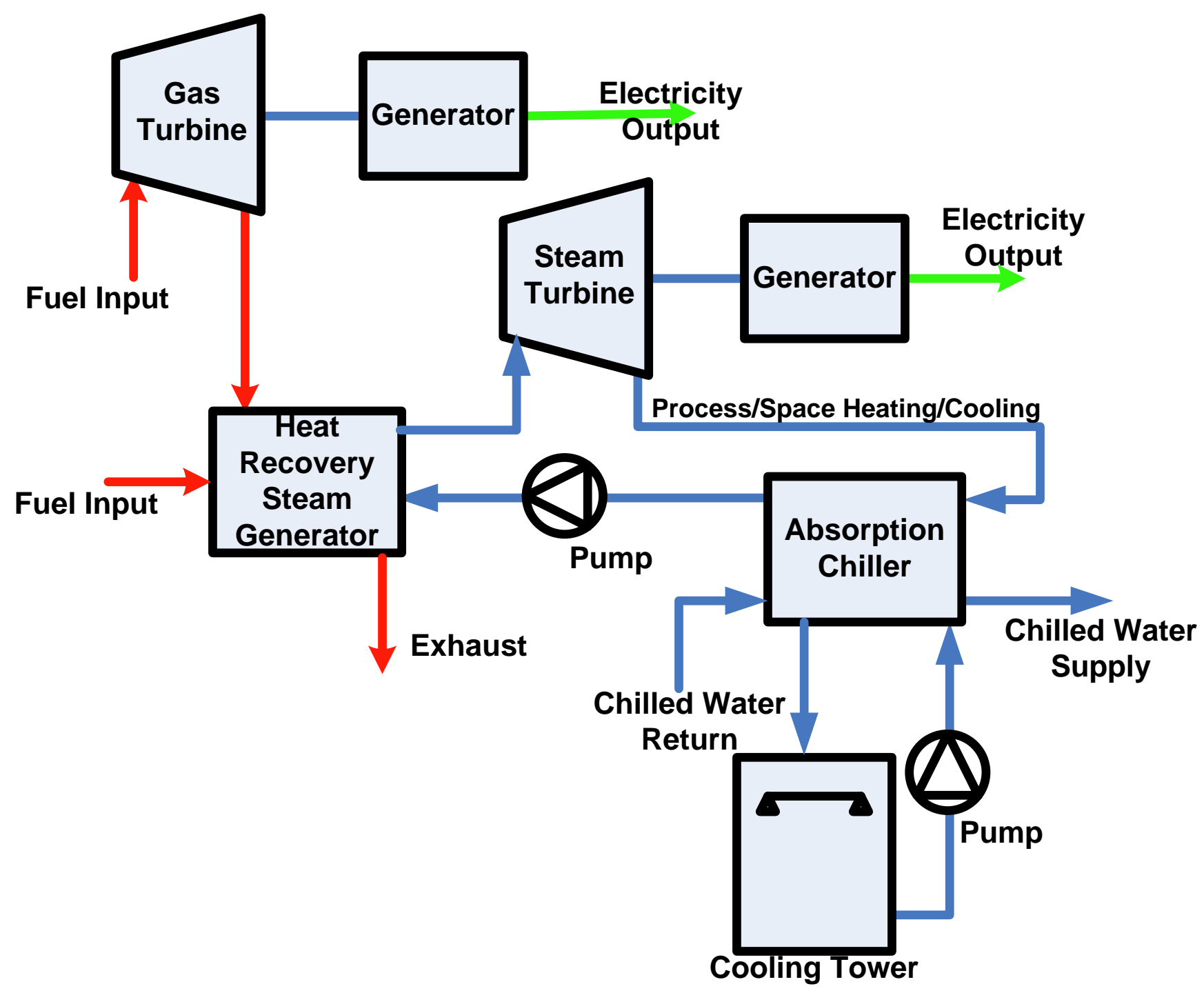

Figure 18 - Gas Turbine with Generator, Heat Recovery Steam Generator, Steam Turbine with Generator, and Steam-Fired Absorption Chiller with Cooling Tower 


\section{Instrumentation and Controls}

Most major components of the CHP system generally have a unitary controller that controls operation of each component (for example, prime mover, absorption chiller, or desiccant system). Although a few fully integrated packaged CHP systems are available in the market, a majority of CHP systems are field designed and assembled. When CHP components are assembled in the field, the individual controllers on each major component are not generally integrated with a system-level or a supervisory controller. There are several reasons for lack of such integration. The most common reason is the use of proprietary controls by some component manufacturers. Some manufacturers use PLCs (programmable logic controller). A few manufacturers provide a choice of the PLC, while others do not. Manufacturers who use PLCs generally support the MODBUS ${ }^{20}$ protocol.

In addition to controlling the operation of the component, some component manufacturers provide rudimentary fault detection capabilities that are built into the controls. For example, an absorption chiller might have a capability to detect crystallization of refrigerant solution during the operation or an ability to shut-off the chiller if certain temperatures or pressures exceed the safe limits. Similarly, micro-turbine manufacturers also provide some fault detection and alarm capabilities, such as warnings when operating the turbine during extreme ambient conditions or when the gas (fuel) pressure is low. These components are generally well instrumented for proper control and to provide fault detection and alarms. They may even have limited diagnostics coupled with automated implementation of protective actions, such as when in response to under or over load or out-of-range frequency/voltage conditions, a microturbine automatically shuts off. Some of the larger systems, such as gas turbines, have even more sophisticated controls. However, although the individual components of the CHP system are physically integrated and have sophisticated instrumentation and individual controls, it is generally very difficult to access the data from the component sensors, and the components are rarely controlled as a single unit using system-level or supervisory controls, which is essential to address many of the needs of CHP system users (which are summarized in the next section).

To control and maintain safe operation of a component, many CHP component manufacturers install sensors to monitor key parameters. For example, one absorption chiller manufacture provides over 15 temperature sensors and several pressure sensors, and a micro-turbine manufacturer provides several temperature sensors, an engine speed sensor, and a sensor to measure electrical properties (voltage, current, and power factor). However, in many cases, it is difficult to access the sensor data for use by supervisory controls or system-level controls without having to install expensive translators or gateways. Furthermore, integration of CHP controls with building automation is difficult but important for integrated operation. Most building automation systems use controls based on proprietary protocols, ASHRAE's BACnet ${ }^{\mathrm{TM}}$ or Echelon's LonWorks ${ }^{\mathrm{TM}}$. Because many CHP component controls generally do not use these protocols, it is often difficult to integrate them with the building automation system.

\footnotetext{
${ }^{20}$ MODBUS is an application layer messaging protocol conforming to level 7 of the OSI model and enables communication between devices. The protocol originally developed by Modicon (http://www.modicon.com) is currently maintained by an independent non-profit organization (http://www.modbus.org).
} 
The algorithms proposed for development in this project require information on many key parameters in the CHP system. The Association of State Energy Research and Technology Transfer Institutes (ASERTTI) long- and short-term monitoring protocols ${ }^{21,22}$ also require many of these parameters. As we develop a more detailed specification of each of the algorithms in the next phase of the work, we will identify sensor requirements of the algorithms, whether the measurements are typically provided by the manufacturer, and whether the ASERTTI protocols require them.

\footnotetext{
${ }^{21}$ Southern Research Institute. 2004. Distributed Generation and Combined Heat and Power Field Testing Protocol, Interim Version. October 27, 2004.

${ }^{22}$ Connected Energy Corporation. 2004. Distributed Generation Combined Heat and Power Long Term Monitoring Protocols, Interim Version. October 29, 2004.
} 


\section{CHP System User Issues and Needs}

In this section, we provide a summary of issues and needs of CHP system owners and users. These were gathered through site visits, phone interviews and review of literature.

The issues and needs can be categorized into three groups: 1) design, 2) reliability of CHP components, and 3) integration.

\section{Design}

Although DOE has been promoting the development and demonstration of integrated packaged CHP systems, most installations we reviewed (which were not DOE projects) are site assembled and not pre-packaged. This may be true for many of the CHP systems currently deployed in the field because CHP systems manufactured as integrated units are still quite new. Because for site assembled systems, many of the components are not tested with each other prior to the installation, many times there are mismatches. An example conveyed to us by a system operator was a mismatch between the exhaust flow from the prime mover and the heat recovery heat exchanger capacity. Another example was the mismatch between the amount of waste heat capacity available and heat required for thermally-activated systems. Although this project will not directly address these problems, several installations reported these sorts of mismatches as an issue, resulting in the need to dump excess waste heat or add auxiliary heat to meet thermal loads.

\section{Reliability}

Reliability can be divided into two major categories: 1) hardware reliability and 2) operational reliability. Because many components for smaller CHP systems $(<1 \mathrm{MW})$ have been developed recently, a few of the first generation components were not reliable. Many installations using the first generation technologies reported reliability to be a problem. However, newer installations with components from the second generation technology are performing better. The current project is not intended to address the hardware reliability issues, but will enhance the operational reliability by developing and deploying the use of performance monitoring, commissioning verification and supervisory controls algorithms with CHP systems.

\section{Integration}

Our interviews and review of literature indicate there are at least four integration challenges. In some cases, it was noted that there were 7 different power sources (AC/DC) that were needed to operate controls and auxiliary devices in the CHP system. Use of mixed units (SI vs. British) in manufacturing also leads to some confusion. In addition, many duplicate sensors had to be installed because it was unreasonably difficult to access values from the factory-installed sensors for other uses. Many CHP systems are not currently sold as a single package; rather they are assembled at the field site with components from different manufacturers who generally use controllers that cannot directly communicate with each other.

To maximize efficiency and minimize operating costs, CHP systems will need to operate as a single unit. Current integration of the various components of CHP systems is insufficient for 
CHP systems to work as single integrated units. For example, users have reported that the lack of coordinating controls between the absorption cooling system and the prime mover resulted in crystallization of the lithium/bromide solution when the chiller tripped and the primer mover was still running thus dumping waste heat into the chiller. The inability to follow thermal loads was also cited as a deficiency caused by lack of integrated controls. Furthermore, with current technology, it is not easy to integrate CHP systems with other building systems and building controls because no standard control protocol is used across CHP components and building systems. Most building automation systems use controls based on proprietary protocols, ASHRAE's BACnet ${ }^{\mathrm{TM}}$ standard, or Echelon's LonWorks ${ }^{\mathrm{TM}}$ open protocol. Because CHP component controls generally do not use open building control system protocols, it is difficult to integrate them with building automation systems.

\section{Needs}

In this sub-section, we list and provide brief descriptions of the needs expressed by owners and operators. In addition, we have also included needs that have been identified through a literature survey. Note that the list below is not in any priority order.

1. Operation decision support and economic dispatch:

Many operators/owners have indicated that they need help in making decisions on whether to self-generate or buy power from the grid, because prices of the energy commodities (electricity, gas, and oil) change over time, and the efficiencies of the CHP components can also change with ambient conditions or the load (electric and thermal). Furthermore, it may be cost-effective to run the CHP system at part-load (to meet thermal demands) rather than run the system at full-load. Tools are needed to support making these decisions.

2. Forecasting of thermal/electric loads for economic dispatch:

In order to minimize the operating cost or run the CHP system optimally, a good tool for forecasting both power and thermal loads is needed - note that this is a sub-set of the operation decision support need described previously.

3. Economic dispatch with dual-fuel capable systems:

Some CHP components have the capability to use multiple fuels. Operators with dualfuel capable CHP systems indicated that they would like to make proper selection of fuel based on the current prices to minimize their energy costs - note that this is a sub-set of operation decision support need described previously.

4. Optimal sequencing of multiple prime movers or thermally activated systems:

A few operators/owners identified the need for an optimal sequencing algorithm that would minimize energy costs when multiple prime movers or thermally activated systems (e.g., absorption systems) of different sizes are inter-connected. Optimal sequencing will 
depend on whether the system is set up to follow thermal or electric load.

5. Emissions monitoring, reporting and control

Many operators of CHP systems have indicated that they would like to track emissions. Some locations have strict emission requirements with penalties for violations, which may require monitoring emissions over time and alerting operators when the emissions exceed or approach emission limits.

6. Inadequate integration of controls

Lack of integrated controls is one of the biggest concerns of operators of small CHP systems $(<1 \mathrm{MW})$. Many CHP systems are field assembled and most often individual component controls are not integrated into a single system-level control. There is a need for a supervisory controller that monitors and controls the entire CHP system.

7. Integration of CHP system controls with building automation systems

Many operators want the CHP system integrated with the existing building/facility automation system. Most CHP installations are not integrated with building automation systems because incompatible communication standards are used by different manufacturers. There is a need to standardize communication protocols or other solutions for integration must be developed.

8. Access to control system data

Some operators indicated a desire to access sensed data collected by the component controls for monitoring conditions directly or using third-party (or their own) software (e.g., SCADA ${ }^{23}$ software) for automatically displaying and analyzing it. Closed proprietary protocols used by controls often prevent doing this, further indicating a desire to see standard open protocols used by the controls and convenient access to sensor data provided.

9. Monitored points insufficient

The number of sensed data points with central reporting is not adequate according to some CHP system operators. One operator indicated that thermocouples were installed to measure the exhaust-gas inlet temperature, exhaust-gas exit temperature, inlet temperature for water, and outlet temperature of hot water from a heat exchanger, but these temperatures were only displayed locally at the heat exchanger. This presented two problems: 1) the temperatures could not be monitored from a central point but required spending time going to the heat exchanger to make readings manually and 2) because the heat exchanger was located outdoors in the sunlight, glare prevented even reading the display under most conditions so effectively there was no monitoring of these points

${ }^{23}$ SCADA represents supervisory control and data acquisition. 
available. This example illustrates a general need for more thorough monitoring and central monitoring for some CHP installations.

10. Optimal coordination of various CHP component operations to maximize efficiency or minimize cost

As noted earlier, many CHP systems are field assembled and in most cases lack integrated system- or application-level controls to monitor, control and integrate with existing building/facility automation systems. Application-level controls, such as supervisory controls also help prevent cascading problems, i.e., if one component of the system is not working properly, they can ensure that other components that rely on the failed component are properly shut down.

\section{Automatic (optimal) thermal load following}

Most CHP systems are designed to follow the electric load because most generators have a built in capability to follow the electric demand imposed on them (until the generator reaches its maximum output). However, in some cases, if all waste heat cannot be utilized, there may be a need to follow the thermal load to minimize total energy cost.

12. Monitoring input contaminants

Moisture and contaminant removal is important for micro-turbines fueled with biogas (e.g., from sewage digesters or landfill gas recovery). Contaminants can cause operation and/or equipment problems. Moisture can be removed to acceptable levels by filtering. Moisture in gas lines can cause condensate which leads to plugging and surging. One CHP system operator identified the need for real-time central monitoring of filter condition or performance with an indicator for when the filter needs replacement.

Siloxane, a class of compounds formed of silicon, oxygen, and alkanes, is found at trace levels in gas produced from waste containing cosmetics, deodorants, toothpastes, hair conditioners, and some soaps. During combustion of gases in reciprocating engines and turbines, siloxanes are converted to silicates and micro-crystalline quartz, which cause corrosion of and deposits on engine surfaces such as turbine blades, engine cylinders, cylinder heads, pistons, valves, spark plugs, and other engine components. ${ }^{24,25,26}$

Siloxane is removed from fuel streams by filtering with absorbent materials. One CHP operation engineer identified the desire to monitor siloxane concentrations in the fuel both upstream and downstream of the filter with an indication of degradation of performance of the filter with use over time so that filter replacement could be based on

\footnotetext{
${ }^{24}$ M. Schweigkofler and R. Niesssner. 2001. "Removal of Siloxanes in Biogases.” Journal of Hazardous 83(3), 183-196.

${ }^{25}$ PpTek Ltd. 2006. "Siloxanes-The Cause, effect, solution." Accessed on the world wide web at http://www.pptek.co.uk/page10.html on May 9, 2006.

${ }^{26}$ P. Tower. 2005. "Biogas Siloxane Damage-The Cost Impact of Biogas Siloxane Contamination." Presentation at the CHP and Bioenergy for Landfills and Wastewater Treatment Plants Workshop held by the Intermountain CHP Center, August 11,2005 in Salt Lake City. Presentation available on the world wide web at http://www.intermountainchp.org/events/landfills/presentations/tower.pdf.
} 
actual filter condition. This would require development of real-time sensing for siloxane. Currently, siloxane measurements in the fuel are determined by periodically sending grab samples of the gas for laboratory processing.

\section{Grid-independent operation difficulties}

In many cases owners would like to use CHP systems to provide local (islanded) backup power during failures of the electric power grid. Although component and system manufacturers claim this as a capability, in some cases, off-grid operation may be difficult or impossible without further system modification. For example, some microturbines are designed to run both on and off grid; however, when installed at locations with low gas-line pressure, they require compressors to boost fuel pressure to the inlet pressure required by the micro-turbine. When grid power is lost, the turbines require (and automatically) shut down. To operate off grid, the micro-turbine must be restarted. Battery backup power is provided to turn the turbine sufficiently for restart but only if fuel gas at adequate pressure is available. The battery backup is not sufficient to both compress the gas adequately and turn the turbine sufficiently to restart under these conditions. A solution such as a backup gas tank maintained at adequate pressure or battery backup sufficient for gas-pressure boosting with a compressor is needed to support practical off-grid operation in such situations. This is a design problem that needs to be solved by the micro-turbine manufacturers or by CHP system designers/installers.

14. Ability to monitor performance of individual components and the CHP system as a whole:

Most component manufacturers provide some built-in monitoring capabilities, but they are limited to instantaneous snapshots of performance. In most cases, no system-level information is provided to the operators. In addition, historical trending of performance is limited. There is a need to provide performance information about the components and the systems, so trends of degradation are clearly visible. 


\section{Project Scope}

In this section, we present a high level description of the algorithms that we propose to develop as part of the multi-year project. Detail specifications for some algorithms, including instrumentation requirements and deployment architecture, will be developed in the next ${ }^{27}$ phase of the project.

The algorithms necessary to address the issues and the needs of the CHP users described in the previous section can be broadly categorized into five major groups as shown in Figure 19: 1) performance monitoring, 2) automated commissioning verification, 3) automated fault detection and diagnostics, 4) automated reconfiguration and correction and 5) supervisory controls. These algorithms are the building blocks to improve operational efficiency of the CHP system.

Performance monitoring algorithms will have to be developed first because both automated fault detection and diagnostics and automated commissioning verification algorithms rely on them. Together the performance monitoring, automated fault detection and diagnostics and automated reconfiguration and correction algorithms form the basis of the conditioned based maintenance.

We will develop algorithms for CHP configurations that use the following components: microturbines and reciprocating engines for primer movers, heat recovery heat exchangers, absorption chillers, cooling towers, and water pumps. Configurations that use this set of components are shown in Figures 9 through 14. Other configurations, although important, will not be supported at this time because of limited resources.

Algorithms for the following purposes will be developed as part of this multi-year effort ${ }^{28}$ :

1. Performance monitoring to track performance of the various CHP components and the CHP system as a whole. These algorithms will help the user/operator of the CHP system monitor the current performance as well as compare it to historical performance. As shown in Figure 19, these sets of performance monitoring algorithms will be the basis for other algorithms to be developed to enhance the operational performance of the CHP system. In addition to the component level alarms that the manufacturers might provide, these algorithms will provide a basis for additional real-time system-level alarms, realtime tracking of the performance indices trends and trend plots.

2. Automated commissioning verification in which proper initial performance (when the unit is started for the first time and periodically thereafter) of each component and the complete CHP system will be verified. This process is intended to ensure that the actual installed performance of each component and the system corresponds with manufacturerspecified performance levels. This capability will enable users/operators to inform installers and manufacturers of problems early in the operational phase and get them corrected. Although this won't solve design problems, it will bring the problems to the attention of the operator early in the operational phase and seek corrections from the

\footnotetext{
${ }^{27}$ As soon as the scope is finalized after discussion with the Project Advisory Panel.

${ }^{28}$ Although we have provide some examples of what to expect in the algorithms, a more detailed list of capabilities will be developed while preparing the detailed specification.
} 
manufacturer or system designer where appropriate.

3. Continuously track system and component performance and automatically detect and diagnose faults ${ }^{29}$ enabling condition-based operation and maintenance. Some examples of the faults that would be detected include: sudden drop in CHP system efficiency or degradation of CHP system efficiency over time, sudden drop in component efficiency or degradation of component efficiency over time. Fouling of heat exchangers and improper control operation and minimize cost are potential causes of component and system performance drops.

4. Supervisory control that enables integrated control and coordination to provide optimal operation of various CHP components to maximize efficiency and minimize cost. Supervisory controls will also help prevent cascading problems, i.e., if one component of the system is not working properly, it will ensure that other components that rely on the faulty component are properly shut down as well or continue operation accounting for the deficiency of the faulty component.

5. Optimal economic dispatch. When the price of energy commodities (electricity, gas, or oil) change over time and the efficiency of the CHP components change with ambient conditions or the load (electric and thermal), optimal economic dispatch algorithms will provide decision support to minimize operational costs. Furthermore, the algorithms will identify and provide guidance regarding when it is cost-effective to run the CHP system at part-load (to meet thermal demands) rather than run the system at full-load. When there are multiple components in the CHP system (multiple chillers or prime movers), these algorithms will help the operator in selecting the right combination of components that would minimize the operating cost for the given load conditions. Algorithms will also be developed to help operators with dual-fuel capable CHP systems to make proper selection of fuel based on the current prices to minimize energy cost. Although load (thermal and electric) is a big determinant of the optimal supervisory control, we don't intend to develop a load forecasting algorithm or tool in this project.

In the first phase of the project (FY06), we will only develop performance monitoring and automated commissioning verification algorithms for most CHP system configurations described previously. The subsequent phases (beyond FY06) will test and validate the algorithms developed in first phase and then develop, test and validate the reminder of the algorithms listed above.

\footnotetext{
${ }^{29}$ Rudimentary system-level automated fault detection and diagnostics algorithms will be developed based on availability of funds.
} 


\section{Economic and Other Data \\ (Energy commodity prices)}

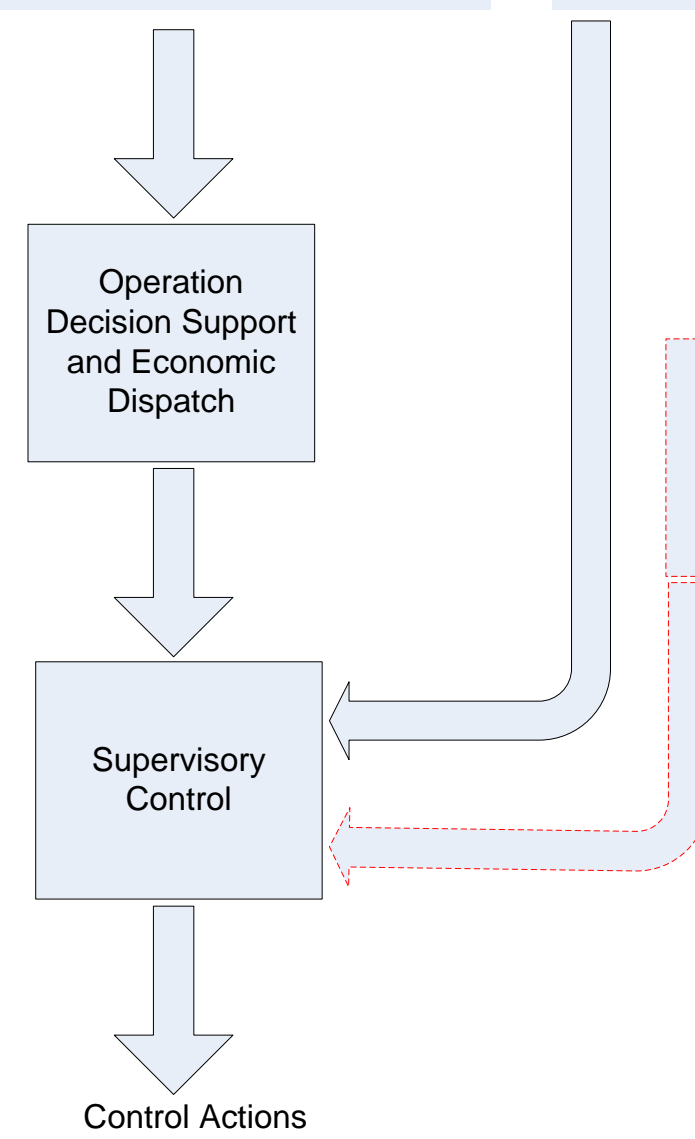

\section{Sensor Data \\ (Energy flows, temperatures, pressures, flow rates, electric power output, etc.)}

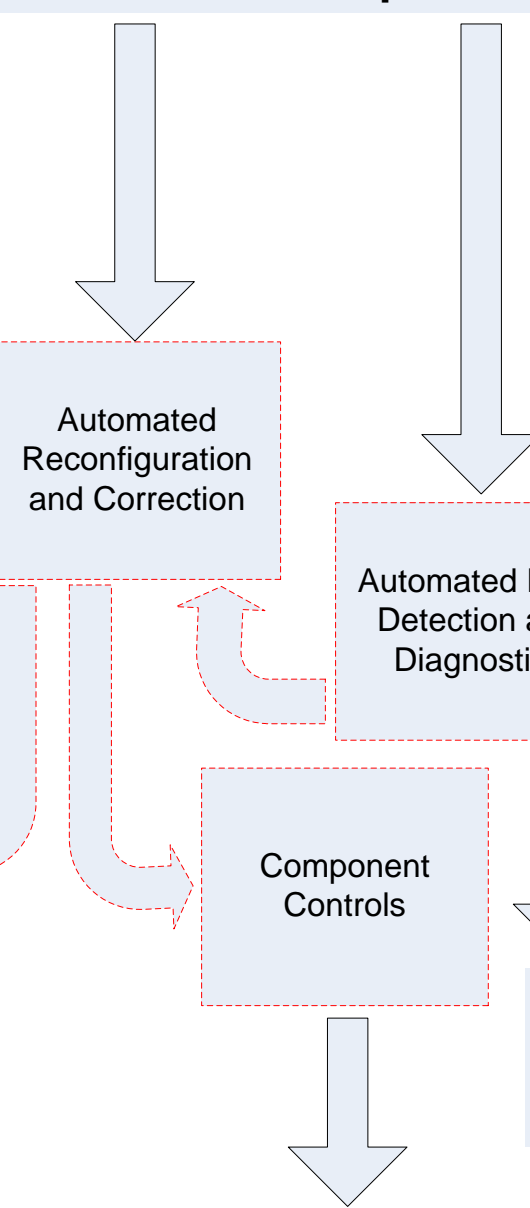

Control Actions

Fault Detection;

Diagnosis of Cause of Fault:

Energy/Cost Impact
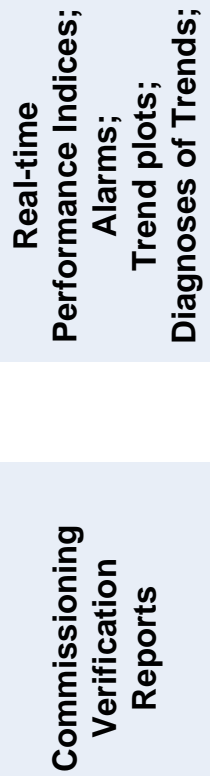

Figure 19 - Major Categories of Algorithms for Advanced Control of CHP systems and the Relationships Among Them (the categories that are in dashed red line will not be developed in the current project) 
